
\title{
28 Research Suare \\ First Evidence of Ommochromes in Bivalves: the Case of the Edible Oyster Crassostrea Gigas
}

\author{
Michel Bonnard \\ Institut des Biomolécules Max Mousseron \\ Bruno Boury \\ Institut Charles Gerhardt \\ Isabelle Parrot ( $\square$ isabelle.parrot-smietana@umontpellier.fr) \\ Institut des Biomolécules Max Mousseron
}

\section{Research Article}

Keywords: variety of pigments, molluscs, ommochromes, bivalves, edible oyster Crassostrea gigas, biosynthetic, melanins and tetrapyrroles

Posted Date: July 12th, 2021

DOI: https://doi.org/10.21203/rs.3.rs-677796/v1

License: @ (i) This work is licensed under a Creative Commons Attribution 4.0 International License. Read Full License 


\section{Abstract}

Among the great variety of pigments found in living beings in general, and more particularly in molluscs, the ommochromes are a family of unknown organic dyes and until now still too little studied. Several lines of physicochemical and structural evidence allowed us here to complete the composition of the purple colour of shell patterns of Crassostrea gigas, highlighting an intriguing association of ommochromes and porphyrins, corroborated by the presence of known genes associated with their biosynthetic pathways. We describe here our pathway to demonstrate for the first time the presence of ommochromes in a bivalve.

\section{Introduction}

Molluscan shell colours are generally attributed to organic pigments, namely carotenoids, melanins and tetrapyrroles ${ }^{1}$. As for many natural products, complexity of their mixture is a general limitation to the determination of their precise distribution and chemical structure. Coloured molecules are also poorly described due to their low content in the shell and the difficulty of their selective extraction from the calcareous material. While the presence of few tetrapyrroles, such as uroporphyrin and biliverdin, are now well established $^{2-4}$, the occurrence of melanins in shells of bivalves is apparently less common than generally expected, as illustrated by the recent work of S. Affenzeller et al. ${ }^{5}$. For instance, the black colour of the adductor muscle scar of shells of the edible oyster Crassostrea gigas, initially hypothesized as a contribution of melanins by S. Hao et al. ${ }^{6}$, was subsequently ruled out without resolving the nature of this colour. We also recently identified uroporphyrin and derivatives in the mantle of $C$. gigas and the purple and dark patterns of its shell ${ }^{7}$. These porphyrins, considered as side-products of the highly conserved haem biosynthetic pathway, constitute an evidence of the haem-based cellular respiration of $C$. gigas ${ }^{8}$. However, it seems clear that these pigments represent only a small proportion of the overall pigments, the other possible candidates being melanins and ommochromes, both potentially supported by the identification, in the mantle, of genes associated with their biosynthetic pathways ${ }^{9}$.

Animal melanins refer to hetero-polycyclic aromatic macromolecules of variable molecular weight resulting from the oxidation of L-tyrosine, giving rise to colours ranging from black to brown, sometimes yellowish and reddish ${ }^{10}$. Their identification as well as their molecular description are limited by their amorphous nature, low solubility in solvents (aqueous and organic) and structural diversity. Spectroscopic investigations such as UV-vis absorption can give a first trend on their potential occurrence, but their unambiguous identification requires the formation of characteristic fragments by alkaline oxidative degradation followed by reverse-phase liquid chromatography (RPLC) combined with mass spectrometry detection (MS) ${ }^{5,11}$. Thus, the identification of pyrrole-2,3-dicarboxylic acid (PDCA) and pyrrole-2,3,5-tricarboxylic acid (PTCA) on the one hand and thiazole-4,5-dicarboxylic acid (TDCA) and thiazole-2,4,5-tricarboxylic acid (TTCA) on the other hand, are respectively representative of eumelanin and pheomelanin, the two types of animal melanins ${ }^{12}$. In some cases, genes involved in their biosynthesis corroborates their occurrence in soft tissues as is now established in different molluscs 
such as Pteria penguin ${ }^{13}$, Hyriopsis cumingii ${ }^{14}$, Pinctada fucata $^{15}$, Pinctada margaritifera $^{16}$, Patinopecten yessoensis ${ }^{17}$, Pinctada fucata ${ }^{18}$. However, this method alone is not sufficient enough to support the presence melanins in shells since the genes might not be expressed by the organism.

Similar to melanins, ommochromes are animal pigments, forming granules in vivo in solid state, with colours ranging from brown to purple, red, orange and yellow ${ }^{19-21}$. Their occurrence is well established in invertebrates, but almost unknown among vertebrates and marine animals to the notable exception of cephalopods $^{22,23}$. As well as melanins, ommochromes presents a macromolecular structure of variable subunits and a low solubility in organic and aqueous solvents without acidifiers, that have severely limited their identification and structural description. Their discrimination from melanins is challenging in a given natural sample which can lead to confusion ${ }^{19,24,25}$. A decisive point of differentiation between ommochromes and melanins lies in their biosynthetic pathway and their respective precursor, ommochromes resulting from the metabolism of L-tryptophan ${ }^{19,26}$ while L-tyrosine is the precursor of animal melanins. Therefore, although the precise chemical structure of ommochromes is generally unknown at present, their occurrence is revealed by the identification of specific biosynthetic metabolites such as 3-hydroxykynurenine (3-HK), 3-hydroxyanthranilic acid (3-HA) and xanthurenic acid (XA) 27,28.

In the present study, a separative extraction combined with advanced RPLC-MS allow us to complete the description of the acid-soluble pigments of the purple patterns of shells of $C$. gigas, among those proposed from the identification of genes associated with their biosynthesis ${ }^{9}$. The unambiguous identification of a key metabolite precursor of ommochromes represents the first evidence of these pigments in a bivalve. This work lead us to define more precisely the composition of the purple colour of C. gigas as an association of ommochromes and porphyrins.

\section{Methods}

Shell fragments. Approximately $1 \mathrm{~kg}$ of shell fragments were collected by hand on living adult oysters in August 2017 (Thau lagoon, Marseillan, France, GPS coordinates: 43.382127, 3.555193). Shell fragments were rinsed with tap water at the farm and transported to the laboratory. Shell fragments were extensively rinsed with tap water and suspended in $0.0155 \mathrm{M} \mathrm{NaOCl}_{(\mathrm{aq})}$ with sonification and regular manual stirring (1:10 wt./ $\mathrm{V}, 120 \mathrm{~min})$. Shell fragments were rinsed several times and suspended in demineralised water with sonification and regular manual stirring (1:10 wt./V, $120 \mathrm{~min})$. Shell fragments were rinsed several times with demineralised water and dried in oven (overnight, $40^{\circ} \mathrm{C}$ ). Shell fragments were sorted in three classes according to their colour. Only fully purple shell fragments were used in this study. Samples were stored in the dark at $25^{\circ} \mathrm{C}$ before use.

Shells of juvenile oysters. Shells of juvenile $C$. gigas were supplied by Tarbouriech-Médithau. Shells were immersed in water bath at $70^{\circ} \mathrm{C}$ to remove the organic materials. Water was regenerated each $2 \mathrm{~h}$ during $8 \mathrm{~h}$ before decontamination which was conducted as for purple shell fragments. 
Absorption profile of acid-soluble pigments. Approximately $10 \mathrm{~g}$ of decontaminated purple fragments of shells of $C$. gigas were dissolved in $1 \mathrm{M} \mathrm{HCl}_{(\mathrm{aq})}$ under magnetic stirring (1:20 wt./V, $\left.30 \mathrm{~min}, 700 \mathrm{RPM}\right)$. The solution of acid-soluble pigments was obtained after filtration on a glass sintered filter (POR 4) filled with Fontainebleau sand. The solution of acid-soluble pigments was filtered on a polyethersulfone syringe filter $(0.22 \mu \mathrm{m})$ and kept at $20^{\circ} \mathrm{C}$ in the autosampler. Separation of the solution of acid-soluble pigments was conducted with a UHPLC-DAD system in the UV-vis range of 200-800 nm (Thermo Scientific Dionex Ultimate 3000). Separation was performed using a $100 \times 4.6 \mathrm{~mm}$ Kinetex $5 \mu \mathrm{m}$ EVO C18 $100 \AA$ reverse stationary phase, operating at $30^{\circ} \mathrm{C}$ with a constant flow rate of $1.0 \mathrm{~mL} / \mathrm{min}$ using two gradients system of ultrapure water $(0.055 \mu \mathrm{S} / \mathrm{cm})$ and acetonitrile, both containing $1 \%$ formic acid $(0$ to $50 \%$ acetonitrile in $53 \mathrm{~min}$ followed by 50 to $100 \%$ acetonitrile in $12 \mathrm{~min}$, followed $100 \%$ acetonitrile in $2 \mathrm{~min}$, followed by $100 \%$ ultrapure water in $0.5 \mathrm{~min}$, followed by $100 \%$ ultrapure water in $9.5 \mathrm{~min}$ ). $\mathrm{V}_{\text {inj: }}: 80 \mu \mathrm{L}$.

Exact mass of acid-soluble pigments. The analysis of acid-soluble pigments was conducted on a Waters Alliances UPLC Synapt G2-S system equipped with an electrospray ionisation source. UV-vis spectra were recorded with a UPLC LG $500 \mathrm{~nm}$ DAD detector from 200 to $500 \mathrm{~nm}$ with a resolution of $1.2 \mathrm{~nm}$ and a sampling rate of 20 points/sec. Separation of acid-soluble pigments was carried out using a $150 \times 2.1$ $\mathrm{mm}$ Kinetex $2.6 \mu \mathrm{m}$ EVO C18 $100 \AA$ reverse stationary phase, operating at $30^{\circ} \mathrm{C}$ with a constant flow rate of $0.5 \mathrm{~mL} / \mathrm{min}$ using ultrapure water $(0.055 \mu \mathrm{S} / \mathrm{cm})$ and acetonitrile HPLC grade as eluents both containing $1 \%$ formic acid. Mass spectra were recorded in the $\mathrm{m} / \mathrm{z}$ range of 50 to 3,000 with a ZQ spectrometer fitted with Micromass Q-Tof spectrometer operating at capillary voltage of $3 \mathrm{kV}$ and cone voltage of $30 \mathrm{~V}$, using phosphoric acid as an internal standard. MassLynx software (version V4.1) was used for instrument control and data processing. Samples were kept at $10^{\circ} \mathrm{C}$ in the autosampler. Appropriate blank analysis was performed before each sample $\left(\mathrm{V}_{\mathrm{inj}}: 10 \mu \mathrm{L}\right)$. Blank TIC chromatogram was systematically subtracted to the corresponding sample TIC chromatogram before data processing. The solution of acid-soluble pigments was filtered on a polyethersulfone syringe filter. Separation was performed with a gradient system acidified with $1 \%$ formic acid: 0 to $50 \%$ acetonitrile in 20 min, followed by 50 to $100 \%$ acetonitrile in $5 \mathrm{~min}$, followed by $100 \%$ acetonitrile in $1 \mathrm{~min}$, followed by $100 \%$ ultrapure water in $0.1 \mathrm{~min}$ and finally 4.9 min with $100 \%$ ultrapure water.

Preparative separation of acid-soluble pigments. The method was first conducted on the solution of acidsoluble pigments obtained from purple fragments of shells of $C$. gigas. The solution of acid-soluble pigments $\left(40 \mathrm{~mL}\right.$ ) was deposited on a $\mathrm{C}_{18}$ grafted silica gel (approximately $40 \mathrm{~g}$ ) previously equilibrated with $1 \mathrm{M} \mathrm{HCl}_{(\mathrm{aq})}$. After deposition, decalcification was performed with $80 \mathrm{~mL} 1 \mathrm{M} \mathrm{HCl}_{(\mathrm{aq})}$ followed by 80 $\mathrm{mL} 0.1 \%$ TFA. Separative elution was performed with $420 \mathrm{~mL}$ of ultrapure water/acetonitrile (80:20 V/V + $0.1 \%$ TFA). The resulting purple fraction was freeze-dried and weighted ( $0.37 \mathrm{wt} . \%)$. Separation was followed with $140 \mathrm{~mL}$ acetonitrile $+0.1 \%$ TFA. The resulting photoluminescent fraction (yellow fraction) was freeze-dried and weighted $(<0.1 \mathrm{wt} . \%)$. This method was repeated on the solution of acid-soluble pigments obtained from purple shells of juvenile $C$. gigas. Approximately $100 \mathrm{~g}$ of shells of juvenile $C$. gigas were dissolved in $1 \mathrm{M} \mathrm{HCl}_{(\mathrm{aq})}$ under magnetic stirring (1:20 wt./V, $\left.30 \mathrm{~min}, 500 \mathrm{RPM}\right)$. The solution of acid-soluble pigments was obtained after filtration on a glass sintered filter (POR 4) filled with 
Fontainebleau sand. Immediately after filtration, the solution of acid-soluble pigments was deposited on a $\mathrm{C}_{18}$ grafted silica gel previously equilibrated with $1 \mathrm{M} \mathrm{HCl}_{(\mathrm{aq})}$. After deposition, decalcification was performed with $200 \mathrm{~mL}$ of $1 \mathrm{M} \mathrm{HCl}_{(\mathrm{aq})}$ followed by $200 \mathrm{~mL}$ of $0.1 \%$ TFA. Separative elution was performed with $1,050 \mathrm{~mL}$ of ultrapure water/acetonitrile (from $95: 5$ to $80: 20 \mathrm{~V} / \mathrm{V}+0.1 \% \mathrm{TFA}$ ). The resulting purple fraction was freeze-dried and weighted (0.039 wt.\%). Separation was followed with $350 \mathrm{~mL}$ acetonitrile + $0.1 \%$ TFA. The resulting photoluminescent fraction was freeze-dried and weighted (0.004 wt.\%).

Solubility and photophysical properties. The qualitative estimation of the PF solubility was conducted at $1 \mathrm{mg} / \mathrm{mL}$ (60 min, $500 \mathrm{RPM}, 20^{\circ}$ ), followed by centrifugation (20 min, 4,400 RPM). Absorption spectra were recorded from 200 to $800 \mathrm{~nm}$ using UV-1800 Shimadzu spectrophotometer (10 mm optical path length). Appropriate auto zero on solvent blank was performed before each measurement. The absorption spectrum of PF was obtained after solubilisation of $1 \mathrm{mg}$ in $1 \mathrm{~mL}$ of $1 \mathrm{M} \mathrm{HCl}_{(\mathrm{aq})}$ and diluted by a factor 10 and 100.

Structural characterisation by tandem mass spectrometry. The purple fraction (1 mg) was solubilised in $200 \mu \mathrm{L}$ of $1 \mathrm{M} \mathrm{HCl}_{(\mathrm{aq})}$ and analysed by RPLC-DAD-Q-ToF-HRMS according to the method employed for the determination of the exact mass of acid-soluble pigments. Automatic MS/MS experiments were conducted using auto transfer collision energy of $2 \mathrm{eV}$. Argon was used as the collision gas. Collisioninduced dissociation mode was performed. MS/MS start $50 \mathrm{Da}$ end $1500 \mathrm{Da}$, number of compound $3 \times 4$, MS/MS switch after $2 \mathrm{sec}$, MS/MS scan time $0.1 \mathrm{sec}$. Peak detection: used intensity based peak detection, peak detection window, charge state tolerance: 0.2 Trap MS/MS collision energy ramp from 30 to $50 \mathrm{eV}$. Cone voltage $40 \mathrm{~V}$. Collision energy ramp low mass $50 \mathrm{Da}$, high mass $1500 \mathrm{Da}$, ramp low mass 10-20 eV ramp high mass $80-140 \mathrm{eV}$.

Screening of metabolite precursors. A solution of $10 \mathrm{mg} / \mathrm{mL}$ of xanthurenic acid was prepared by solubilisation in $1 \mathrm{~mL}$ of $1 \mathrm{M} \mathrm{HCl}_{(\mathrm{aq})}$ under magnetic stirring (60 min, $700 \mathrm{RPM}$ ), followed by filtration on polyethersulfone syringe filter $(0.22 \mu \mathrm{m})$, XA being slightly soluble in water. The resulting solution was analysed by RPLC-DAD-Q-ToF-HRMS according to the method previously employed. MS/MS experiments were performed in collision-induced dissociation mode with a trap collision energy ramp from 15 to $40 \mathrm{eV}$ and using auto transfer collision energy of $2 \mathrm{eV}$. Argon was used as the collision gas.

Comparative analysis with natural eumelanin. The oxidation was conducted with $10 \mathrm{mg}$ of $\mathrm{PF}$, ultrapure water $(1 \mathrm{~mL}), 1 \mathrm{M} \mathrm{K}_{2} \mathrm{CO}_{3(\mathrm{aq})}(3.75 \mathrm{~mL})$ and $30 \% \mathrm{H}_{2} \mathrm{O}_{2(\mathrm{aq})}(250 \mu \mathrm{L})$, under magnetic stirring (20 hours, 500 $\mathrm{RPM}, 20^{\circ} \mathrm{C}$ ). $500 \mu \mathrm{L}$ of $10 \% \mathrm{Na}_{2} \mathrm{SO}_{3(\mathrm{aq})}$ was added. $550 \mu \mathrm{L}$ of the solution was mixed with $140 \mu \mathrm{L}$ of $6 \mathrm{M}$ $\mathrm{HCl}_{(\mathrm{aq})}$. After centrifugation (20 min, 4,400 RPM), the supernatant was collected and purified by solid phase extraction (Strata-X $200 \mathrm{mg}$ Phenomenex). Conditioning was conducted with methanol $(6 \mathrm{~mL})$ followed by ultrapure water $(6 \mathrm{~mL})$. After sample loading, washing was conducted with $0.3 \%$ aqueous formic acid $(3 \mathrm{~mL})$. Elution was conducted with methanol $(3 \mathrm{~mL})$ and ethyl acetate $(3 \mathrm{~mL})$. The collected fraction was evaporated under a constant flux of argon during approximately $5 \mathrm{~h}$. After evaporation, the solid residue was solubilised in ultrapure water $(200 \mu \mathrm{L})$ and analysed by RPLC-Q-ToF-HRMS with the previously described Waters Alliances UPLC Synapt G2-S system in electrospray negative ionisation 
mode. Separation was carried out using a $100 \times 2.1 \mathrm{~mm}$ Kinetex $1.7 \mu \mathrm{m}$ EVO C18 $100 \AA$ 住erse stationary phase, operating at $45^{\circ} \mathrm{C}$ with a constant flow rate of $0.2 \mathrm{~mL} / \mathrm{min}$ using ultrapure water $(0.055$ $\mu \mathrm{S} / \mathrm{cm}$ ) and acetonitrile HPLC grade as eluents both containing $1 \%$ formic acid. Mass spectra were recorded in the $m / z$ range of 50 to 1,500 with a ZQ spectrometer fitted with Micromass Q-Tof spectrometer operating at capillary voltage of $2.4 \mathrm{kV}$ and cone voltage of $30 \mathrm{~V}$, using phosphoric acid as an internal standard. MassLynx software (version V4.1) was used for instrument control and data processing. Samples were kept at $10^{\circ} \mathrm{C}$ in the autosampler $\left(\mathrm{V}_{\mathrm{inj}}: 10 \mu \mathrm{L}\right)$. Separation was performed with a gradient system acidified with 1\% formic acid: 0 to $20 \%$ acetonitrile in $20 \mathrm{~min}$, followed by 20 to $100 \%$ acetonitrile in $1 \mathrm{~min}$, followed by 100\% acetonitrile in $2 \mathrm{~min}$, followed by 100\% ultrapure water in $0.1 \mathrm{~min}$ and finally 4.9 min with $100 \%$ ultrapure water. The entire process was repeated with $10 \mathrm{mg}$ of Sepia officinalis eumelanin.

Solvents and reagents. Acetonitrile HPLC grade ( $\geq 99.9 \%)$ was purchased from Fisher Scientific (Belgium). $\mathrm{C}_{18}$ grafted silica for flash high throughput purification was purchased from Supelco (USA, batch SP98226 and SP10816). Fontainebleau sand was purchased from VWR Chemicals (Belgium). Formic acid ULC/MS grade (99\%) was purchased from Biosolve (Netherlands). Hydrochloric acid 37\% was purchased from VWR Chemicals (France). Hydrogen peroxide $30 \%$ was purchase from VWR Chemicals (France). Sodium hypochlorite 9.6\% was purchased from Notilia. Sodium sulfite was purchased from VWR Chemicals (France). Methanol HPLC grade ( $\geq 99.9 \%$ ) was purchased from Fisher Scientific (Belgium). Sepia officinalis eumelanin was purchased from Sigma-Aldrich (USA, batch \#103H1023). Trifluoroacetic acid HPLC grade was purchased from Fisher Scientific (United Kingdom). Ultrapure water $(0.055 \mu \mathrm{S} / \mathrm{cm})$ were obtained by pre-filtration and reverse osmosis system (LaboStar PRO TWF, Evoqua Water Technologies). Xanthurenic acid was purchased from Interchim (France, batch V0226P002).

\section{Results}

Absorption profile of acid-soluble pigments. After collection and decontamination, purple fragments of shells of $C$. gigas were dissolved in aqueous hydrochloric acid and analysed, after filtration, by reverse phase liquid chromatography monitored by UV-vis detection from 200 to $800 \mathrm{~nm}$ in 3D-field acquisition mode. In these conditions, acid-soluble pigments were separated as shown in Supplementary Fig. 1. Among the six major signals observed on the chromatogram at $405 \mathrm{~nm}$, the UV-vis absorption profile of the compound eluted at $30.08 \mathrm{~min}$ is characteristic of uroporphyrin I or III on the basis of its Soret and Q bands (Fig. 1) ${ }^{7}$. The major compounds eluted from 12 to $23 \mathrm{~min}$ have a broad absorption band from approximately 430 to $600 \mathrm{~nm}$, with $\lambda_{\max }$ ranging from 530 to $486 \mathrm{~nm}$ (Fig. 1). Their absorption profiles significantly differ from those of melanins which are characterised by a continuous decreasing absorption towards the visible region without characteristic bands from 400 to $800 \mathrm{~nm}^{29}$. They also differ from those of porphyrins since no Soret band at $\approx 400 \mathrm{~nm}$ is distinguishable. These profiles turn out to be comparable to those of ommochromes which present a large band from 400 to $600 \mathrm{~nm}$ and a smaller one around 310 or $380 \mathrm{~nm}$ depending on the $\mathrm{pH}$ and the pigment in question ${ }^{19,22,30}$. 
These observations are consistent with the fact that the purple colour of the shell patterns of $C$. gigas cannot be solely attributed to uroporphyrin and derivatives. In this context, ommochromes are interesting candidates, once carotenoids and animal eumelanin are initially excluded since they are not soluble under the aqueous acidic conditions employed in this study.

Exact mass of acid-soluble pigments. The absorption signature of ommochromes combined with diodearray detectors and mass spectrometers makes their identification and structural description more and more achievable ${ }^{27}$. In this study, the acid-soluble pigments were analysed by reverse-phase liquid chromatography monitored by high-resolution mass spectrometry (RPLC-Q-ToF-HRMS) and UV-vis (200$500 \mathrm{~nm}$ ) detection, for the determination of their exact mass. Under these conditions, detection at $500 \mathrm{~nm}$ allows to select seven major signals from the chromatogram ranging from 8 to $11 \mathrm{~min}$ (Fig. 2a). Detection at $405 \mathrm{~nm}$ is less informative on the 8-11 min region (Fig. 2b), but allows to identify uroporphyrin I or III at 13.35 min corresponding to molecular ion $[\mathrm{M}+\mathrm{H}]^{+}$at $m / z 831.2367$, Fig. $2 \mathrm{~d}$.

The examination of the mass spectra of the major signals is dominated by a series of molecular ions with a state of charge of 2, as exemplified for the signal at $8.30 \mathrm{~min}$ in Fig. 2c. Molecular ions with a state of charge of 3 were also observed. Their mass spectra are characterised by multiple molecular ions for a given retention time (Supplementary Table 1 and Supplementary Fig. 2). In the example of signal 1 (Fig. 2c), starting from $[\mathrm{M}+2 \mathrm{H}]^{2+}$ at $m / z 700.6772$, the signal at $m / z 722.6692$ may correspond to $[\mathrm{M}+$ $\left.\mathrm{CO}_{2}+2 \mathrm{H}\right]^{2+}$, the signal at $m / z 723.6802$ may correspond to $\left[\mathrm{M}+\mathrm{HCO}_{2} \mathrm{H}+2 \mathrm{H}\right]^{2+}$, the signal at $m / z$ 730.6688 may correspond to $\left[\mathrm{M}+\mathrm{CO}_{2}+\mathrm{O}+2 \mathrm{H}\right]^{2+}$, the signal at $m / z 739.6747$ may correspond to $[\mathrm{M}+$ $\left.\mathrm{CO}_{2}+\mathrm{O}+\mathrm{H}_{2} \mathrm{O}+2 \mathrm{H}\right]^{2+}$ and the signal at $m / z 763.6595$ may correspond to $\left[\mathrm{M}+\mathrm{HCO}_{2} \mathrm{H}+\mathrm{SO}_{3}+2 \mathrm{H}\right]^{2+}$. Accordingly, their exact mass is given in Supplementary Table 1. In first analysis, this feature can be representative of carboxylated/decarboxylated, oxidised/reduced, hydroxylated, hydrated, sulphated and potentially esterified concomitant ions. The formation of adducts is also possible (formic acid and water adducts). Fragmentation by tandem mass spectrometry was investigated in order to define more precisely their structures but the intensity of ions was not sufficient to obtain exploitable structural information for the definition of their molecular formula. The recorded exact masses of these acid-soluble pigments are significantly higher than those reported among known molluscan shell pigments ${ }^{1,31}$. Only the polymeric or oligomeric nature of melanins and ommochromes can display such high masses.

All together, these data represent additional evidences that the acid-soluble pigments are constituted by two groups, porphyrins and potentially ommochromes or pheomelanin, eumelanin being not acid-soluble.

To get forwards, the two sets of acid-soluble pigments were separated by preparative chromatography in open system, leading to a purple and a photoluminescent fraction. The purple fraction (PF), corresponding to the major pigments previously observed in Fig. 2a, was further characterized in order to define the occurrence or absence of ommochromes and/or pheomelanins.

Solubility and photophysical properties. Ommochromes are well-known to be insoluble in most aqueous and organic solvents, but soluble in acidified conditions (hydrochloric acid) ${ }^{22}$, a notable difference with 
eumelanin. In this part of our work, the solubility of the PF powder was investigated with a specific focus regarding data reported in the literature. The qualitative estimation of PF solubility (Table 1) shows an important solubility in acidified solvent, especially in a hydrochloric acid methanol solution. This agrees with the solubility of ommochromes, described as slightly soluble in methanol but turning fully soluble with the addition of a concentrated aqueous solution of $\mathrm{HCl}$. In addition, the solubility of PF in alkali solution is also describe as compatible with ommochromes, although causing degradation ${ }^{32,33}$.

Table 1

Qualitative estimation of the solubility of PF.

\begin{tabular}{|c|c|}
\hline Solvents & Solubility \\
\hline Acetic acid (1M, aqueous) & +++ \\
\hline Acetone & - \\
\hline Cyclohexane & - \\
\hline Chloroform & - \\
\hline Dichloromethane & - \\
\hline Diethyl ether & - \\
\hline Ethanol & + \\
\hline Ethyl acetate & - \\
\hline Isopropyl alcohol & - \\
\hline Hexane & - \\
\hline Hydrochloric acid (1M, aqueous) & +++ \\
\hline Methanol & + \\
\hline Methanol containing $1 \%$ of $12 \mathrm{M} \mathrm{HCl}_{(\mathrm{aq})}$ & +++ \\
\hline Methanol containing $0.1 \%$ of $12 \mathrm{M} \mathrm{HCl}_{(\mathrm{aq})}$ & +++ \\
\hline Sodium hydroxide (1M, aqueous) & +++ \\
\hline Ultrapure water & + \\
\hline
\end{tabular}

Another point of differentiation among molluscan shell pigments lies in their fluorescent property in solution. Since only tetrapyrroles are photoluminescent, any photoluminescence was reported in the literature from solutions of ommochromes ${ }^{34}$. In line with the literature, without much surprise, we observed no photoluminescence under 254, 360 and $400 \mathrm{~nm}$ for the acid solution of PF. Both absorption spectra of PF and the initial solution of acid-soluble pigments have the same absorption profile (Fig. 3), characterised by an absorption band at $360 \mathrm{~nm}$ and a large band from 400 to $600 \mathrm{~nm}$ with $\lambda_{\max } 464,496$ and $552 \mathrm{~nm}$, representative of the major ommochrome or pheomelanin pigments (Fig. 1). 
Structural characterisation of the purple fraction by tandem mass spectrometry. PF solubilised in $1 \mathrm{M}$ $\mathrm{HCl}_{(\mathrm{aq})}$ at $5 \mathrm{mg} / \mathrm{mL}$ was investigated by tandem fragmentation mass spectrometry after chromatographic separation. In positive ionisation mode, the major double-charged parent ion previously observed at $\mathrm{m} / z 722.6$ led to, at least, six successive neutral loss of $\mathrm{CO}_{2}$ until the double-charged product ion at $\mathrm{m} / z 581.6984$ (Fig. 4a-b). Between $\mathrm{m} / z 581.6984$ and 299.1008 , signal intensity was too low to attribute mass losses. Between monocharged ions at $m / z 299.1008$ and 172.0361 , a neutral loss of 125.0474 Da can be potentially assigned to $\mathrm{C}_{6} \mathrm{H}_{7} \mathrm{NO}_{2}$. As well, the ion at $m / z 174.0534$ may be potentially assigned to $\mathrm{C}_{10} \mathrm{H}_{8} \mathrm{NO}_{2}{ }^{+}$. However, on the basis of this fragmentation pattern alone, the number of possible molecular formulas with only $\mathrm{CHNO}$ atoms for this double-charged ion can only be restricted to three $\left(\mathrm{C}_{62} \mathrm{H}_{65} \mathrm{~N}_{3} \mathrm{O}_{37}, \mathrm{C}_{75} \mathrm{H}_{57} \mathrm{~N}_{5} \mathrm{O}_{26}, \mathrm{C}_{63} \mathrm{H}_{61} \mathrm{~N}_{7} \mathrm{O}_{33}\right)$. Another major double-charged ion at $\mathrm{m} / \mathrm{z} 762.6$ was investigated by tandem mass fragmentation (Fig. $4 \mathrm{c}-\mathrm{d}$ ). Four intense monocharged product ions at $\mathrm{m} / \mathrm{z}$ $130.0293,186.0197,204.0279$ and 232.0233 , corresponding respectively to $\mathrm{C}_{8} \mathrm{H}_{4} \mathrm{NO}^{+}, \mathrm{C}_{10} \mathrm{H}_{4} \mathrm{NO}_{3}{ }^{+}$, $\mathrm{C}_{10} \mathrm{H}_{4} \mathrm{NO}_{3}{ }^{+}$and $\mathrm{C}_{11} \mathrm{H}_{6} \mathrm{NO}_{5}{ }^{+}$were observed.

In negative ionisation mode, five major double-charged ions at $m / z 722.6521$ (1447.3198 Da), 730.6509 (1463.3174 Da), 744.6485 (1491.3126 Da), 752.6451 (1507.3058) and 763.6391 (1529.2938 Da) were investigated (Fig. 5a-e). Multiple neutral losses of $\mathrm{CO}_{2}$ were distinguished, at least nine for the ion at $\mathrm{m} / z$ 722.6, six for the ion at $m / z 730.6$, eight for the ion at $m / z 744.6$, seven for the ion at $m / z 752.6$ and four for the ion at $m / z$ 763.6. In each case, an intense monocharged product ion was observed at $\mathrm{m} / \mathrm{z}$ 160.039 , suggesting that these compounds share a common sub-molecular unit.

Differently from double-charged ions reported here, the molecular formulas of some monocharged ions were obtained from tandem mass fragmentation data in both positive and negative ionisation mode (Table 2). The product ions formed during the fragmentation of their corresponding parent ions (Supplementary Fig. 4) were common to those observed on some double-charged ions. For example, the compound $\# 1$, with a parent molecular ion $[\mathrm{M}+\mathrm{H}]^{+}$at $m / z 457.0890\left(\mathrm{C}_{21} \mathrm{H}_{16} \mathrm{~N}_{2} \mathrm{O}_{10}{ }^{+}\right)$led to product ions at $m / z$ 232.0255, 204.0290, 186.0189 and 130.0298 (Fig. 6a), already observed in Fig. 4d. In negative ionisation mode, the product ion at $m / z 160.0396$ was also observed (Fig. 6b), as reported for the major double-charged ions (Fig. 5). In addition, the fragmentation spectrum of compound \#1 shows that, after the neutral loss of two $\mathrm{CO}_{2}$ ascribed to carboxylic acid functions, Fragment $\mathrm{A}^{-}$leads to two fragmentation patterns (Fragment $\mathrm{B}^{-}$and Fragment $\mathrm{C}^{-}$), suggesting that compound $\# 1$ is constituted by two sub-units. 
Table 2

Major monocharged ions identified in PF.

\begin{tabular}{|c|c|c|c|c|}
\hline Compounds & $\begin{array}{l}\text { Major molecular } \\
\text { ions } \\
{[\mathrm{M}+\mathrm{H}]^{+}} \\
\mathrm{m} / \mathrm{z}\end{array}$ & $\begin{array}{l}\text { Exact } \\
\text { mass } \\
(\mathrm{Da})\end{array}$ & $\begin{array}{l}\text { Molecular } \\
\text { formula }\end{array}$ & Double bound equivalent \\
\hline$\# 1$ & 457.0895 & 456.0805 & $\mathrm{C}_{21} \mathrm{H}_{16} \mathrm{~N}_{2} \mathrm{O}_{10}$ & 15 \\
\hline \#2 & 443.0715 & 442.0648 & $\mathrm{C}_{20} \mathrm{H}_{14} \mathrm{~N}_{2} \mathrm{O}_{10}$ & 15 \\
\hline \#3 & 471.1050 & 470.0961 & $\mathrm{C}_{22} \mathrm{H}_{18} \mathrm{~N}_{2} \mathrm{O}_{10}$ & 15 \\
\hline \#4 & 638.1235 & 637.1180 & $\mathrm{C}_{29} \mathrm{H}_{23} \mathrm{~N}_{3} \mathrm{O}_{14}$ & 20 \\
\hline \#5 & 656.1369 & 655.1286 & $\mathrm{C}_{29} \mathrm{H}_{25} \mathrm{~N}_{3} \mathrm{O}_{15}$ & 19 \\
\hline \#6 & 672.1334 & 671.1235 & $\mathrm{C}_{29} \mathrm{H}_{25} \mathrm{~N}_{3} \mathrm{O}_{16}$ & 19 \\
\hline$\# 7$ & 680.1383 & 679.1286 & $\mathrm{C}_{31} \mathrm{H}_{25} \mathrm{~N}_{3} \mathrm{O}_{15}$ & 21 \\
\hline \multicolumn{5}{|c|}{ Other monocharged ions detected but not fragmented } \\
\hline \#8 & 407.0561 & 406.0437 & $\mathrm{C}_{20} \mathrm{H}_{10} \mathrm{~N}_{2} \mathrm{O}_{8}$ & 17 \\
\hline$\# 9$ & 411.0818 & 410.0750 & $\mathrm{C}_{20} \mathrm{H}_{14} \mathrm{~N}_{2} \mathrm{O}_{8}$ & 15 \\
\hline$\# 10$ & 415.1185 & 414.1063 & $\mathrm{C}_{20} \mathrm{H}_{18} \mathrm{~N}_{2} \mathrm{O}_{8}$ & 13 \\
\hline$\# 11$ & 417.0920 & 416.0856 & $\mathrm{C}_{19} \mathrm{H}_{16} \mathrm{~N}_{2} \mathrm{O}_{9}$ & 13 \\
\hline$\# 12$ & 429.0923 & 428.0856 & $\mathrm{C}_{20} \mathrm{H}_{16} \mathrm{~N}_{2} \mathrm{O}_{9}$ & 14 \\
\hline$\# 13$ & 439.0794 & 438.0699 & $\mathrm{C}_{21} \mathrm{H}_{14} \mathrm{~N}_{2} \mathrm{O}_{9}$ & 16 \\
\hline$\# 14$ & 445.0882 & 444.0805 & $\mathrm{C}_{20} \mathrm{H}_{16} \mathrm{~N}_{2} \mathrm{O}_{10}$ & 14 \\
\hline \#15 & 459.1028 & 458.0916 & $\mathrm{C}_{21} \mathrm{H}_{18} \mathrm{~N}_{2} \mathrm{O}_{10}$ & 14 \\
\hline$\# 16$ & 461.0815 & 460.0754 & $\mathrm{C}_{20} \mathrm{H}_{16} \mathrm{~N}_{2} \mathrm{O}_{11}$ & 14 \\
\hline$\# 17$ & 473.0836 & 472.0745 & $\mathrm{C}_{21} \mathrm{H}_{16} \mathrm{~N}_{2} \mathrm{O}_{11}$ & 15 \\
\hline$\# 18$ & 481.1118 & 480.1016 & $\mathrm{C}_{20} \mathrm{H}_{20} \mathrm{~N}_{2} \mathrm{O}_{12}$ & 12 \\
\hline
\end{tabular}

The sum of these data indicates that the major pigments detected in PF have a common sub-molecular structural basis, in addition to being polycarboxylated. The molecular formula and double bound equivalent (or level of unsaturation) of compounds forming monocharged ions are compatible with the 
ommochromes described by S. Panettieri et al. ${ }^{27}$, especially those with esterified functions such as ahydroxy xanthommatin methyl ester $\left(\mathrm{C}_{21} \mathrm{H}_{14} \mathrm{~N}_{2} \mathrm{O}_{9}\right.$, DBE of 16$)$ that may correspond to compound \#13. Unfortunately, tandem mass fragmentation data below $\mathrm{m} / \mathrm{z} 300$ were not reported which limits data comparison.

Screening of metabolite precursors. To date, only fourteen structures of ommochrome have been described by mass spectrometry, all related to the class of ommatin, the most described class of ommochromes ${ }^{22}$. However, the precise identification and structural description of ommochrome pigments is not always possible in natural samples. For example, the red, red-brown and yellow pigments of wings of Junonia coenia (common buckeye) were assigned to dihydroxanthommatin, ommatin D and xanthommatin on the basis of UV-vis absorption and thin layer chromatography, but none were detected by RPLC-MS-MS/MS ${ }^{35,36}$. Today, only xanthurenic acid was identified among intermediate metabolites of ommochromes. Therefore, based on the literature, the identification of xanthurenic acid constitutes an alternative approach for the identification of ommochrome pigments in a natural sample $\mathrm{e}^{28,37}$.

Consequently, the molecular ions of the known metabolite precursors and side products of the ommochromes biosynthesis (tryptophan, formylkynurenine, kynurenine, 3-hydroxykynurenine, xanthurenic acid (XA), kynurenic acid (KA), anthranilic acid (AA) were retrieved from the data obtained by the RPLC-Q-ToF-HRMS analysis of PF. Three molecular ions potentially corresponding to anthranilic acid, kynurenic acid and xanthurenic acid were identified (Table 3, Supplementary Fig. 5).

Table 3

Metabolite precursors identified in PF.

\begin{tabular}{|lllll|}
\hline Compounds & $\begin{array}{l}\text { Molecular formula and } \\
\text { Exact mass }(\mathrm{Da})\end{array}$ & Retention time $(\mathrm{min})$ & $\mathrm{m} / \mathbf{z}[\mathrm{M}+\mathrm{H}]^{+}$ & $\begin{array}{l}\text { Exact mass } \\
(\mathrm{Da})\end{array}$ \\
\hline Anthranilic acid & $\mathrm{C}_{7} \mathrm{H}_{7} \mathrm{NO}_{2}$ & 3.71 & 138.0548 & 137.0475 \\
& $137.0477 \mathrm{Da}$ & & $(\Delta-5.1 \mathrm{ppm})$ & \\
\hline Kynurenic acid & $\mathrm{C}_{10} \mathrm{H}_{7} \mathrm{NO}_{3}$ & 4.50 & 190.0505 & 189.0427 \\
& $189.0426 \mathrm{Da}$ & & $(\Delta+0.5 \mathrm{ppm})$ & \\
\hline Xanthurenic acid & $\mathrm{C}_{10} \mathrm{H}_{7} \mathrm{NO}_{4}$ & 4.89 & 206.0453 & 205.0375 \\
& 205.0375 & & $(\Delta 0 \mathrm{ppm})$ & \\
\hline
\end{tabular}

The identification of XA is of particular interest since it is described as a precursor as well as a side or degradation product related to the biosynthetic pathway of ommochromes ${ }^{28}$. Its identification in PF, also identified from purple fragments of shells dissolved in $\mathrm{HCl}_{(\mathrm{aq})}$ (Supplementary Fig. 6), was confirmed by the comparative RPLC-Q-ToF-HRMS-MS/MS analysis of a commercial standard, eluted at 5.03 min (Fig. 7). Fragmentation performed in tandem mass spectrometry in negative ionisation mode shows a 
product ion at $\mathrm{m} / z 160.0400$ corresponding to the mass of $\mathrm{C}_{9} \mathrm{H}_{6} \mathrm{NO}_{2}{ }^{-}$(Fig. $7 \mathrm{~d}, \mathrm{e}$ ), previously observed during the structural characterisation of acid-soluble pigments from PF (Figs. 5 and $6 \mathrm{~b}$ ). It suggests that the acid-soluble pigments of PF are constituted by a decarboxylated XA sub-unit, which is highly characteristic of ommochromes.

Comparative analysis with natural eumelanin. In order to unambiguously identify to presence or absence of eumelanin and pheomelanin in PF, we transposed the method recently reported by S. Affenzeller et al. ${ }^{5}$ evidencing the absence of melanins in black adductor muscle scar of the shell of $C$. gigas. After alkaline oxidation ( $10 \mathrm{mg}, 20^{\circ} \mathrm{C}, \mathrm{H}_{2} \mathrm{O}_{2(30 \%)}$, 20 hours), RPLC-Q-ToF-HRMS analysis was compared to a sample of natural Sepia officinalis eumelanin as a positive control and treated in the same condition. From the eumelanin control from Sepia officinalis, the molecular ions of PDCA ([M-H] $]^{-} \mathrm{m} / \mathrm{z}$ at 154.0148) and PTCA $\left([\mathrm{M}-\mathrm{H}]^{-} \mathrm{m} / \mathrm{z}\right.$ at 198.0046) were detected at $1.59 \mathrm{~min}$ (Fig. 8a-b). In contrast, none of the eumelanin and pheomelanin markers were identified in the oxidised PF (Fig. 8c-f), strongly supporting the absence of melanins in the acid-soluble pigments of the purple patterns of the shell of $C$. gigas.

\section{Discussion}

In molluscs of different taxa or even in a single taxon, "similar shell colours can arise from different pigments" ${ }^{3}$. Conversely, a given group of pigments can produce different shell colours ${ }^{3}$. In this study, we noted that at least two groups of acid-soluble pigments were involved in the purple colour of shells of the oyster $C$. gigas. Among possible groups proposed from the identification of genes associated with their biosynthesis ${ }^{9}$, while the presence of acid-soluble porphyrins represented here by uroporphyrin I or III is now well established ${ }^{7,8}$, the presence of carotenoids and eumelanin could be ruled-out, their solubility being not compatible $1,30,38,39$. Besides, after separations of porphyrins from the set of acid-soluble pigments, the resulting PF was slightly soluble at $1 \mathrm{mg} / \mathrm{mL}$ in methanol, turning fully soluble with the addition of $\mathrm{HCl}_{(\mathrm{aq})}$, a typical property of ommochrome pigments. Differently from porphyrins or other nonmolluscan shell pigments like pterins, flavonoids and papilochromes, the acid-soluble pigments in PF are not photoluminescent under UV light, which is consistent with carotenoids, melanins and ommochromes $^{34}$. At this stage, if carotenoids were ruled out, the assignation of acid-soluble pigments other than porphyrins to the group of ommochromes cannot be certified, since pheomelanin may also be valid.

Pioneering studies on ommochromes have proposed a subdivided classification according to their dialysis profile: ommatins (rather dialyzable), ommins (almost non-dialyzable) and ommidins (intermediate). The structures of approximately fourteen natural ommatins were established by mass spectrometry, but the structures of ommins and ommidins are much less described so far. For example, the well accepted structure of ommin $A^{22,40}$ (Fig. 9) is solely based on chemical properties and elemental determination ${ }^{19,33}$. Besides, ommidins have completely disappeared from experimental investigations subsequent to the work of B. Linzen in $1974^{19}$. Only a recent article point out their possible occurrence in 
invertebrates ${ }^{22}$, but no characteristic and unambiguous structures or precise physicochemical properties have been reported to date.

Our data show that the absorption spectra of acid-soluble pigments other than porphyrins (Fig. 1) are comparable to those of ommochromes. While ommatins have an absorption band with a $\lambda_{\max }$ around 450-500 nm, ommin A absorbs around $520 \mathrm{~nm}$. The wide absorption band of PF, from 400 to $600 \mathrm{~nm}$ with $\lambda_{\max }$ at 464,496 and $552 \mathrm{~nm}$, can result from a combination of various ommochromes pigments ${ }^{30}$ (ommatins and ommins, at least). The discrimination between pheomelanin and ommochromes was then conducted by alkaline oxidation of PF, where none of pheomelanin markers were identified. In line with this result and those reported by S. Affenzeller et al. ${ }^{5}$, if melanins are deposited in the coloured parts of the shell of $C$. gigas, they do not constitute a part of the set of acid-soluble pigments.

The identification of xanthurenic acid in PF, strongly support the presence of ommochromes. In invertebrates, XA is described as a key metabolite of the biosynthesis of ommochromes ${ }^{19,22,28}$, exclusively related to this biological route ${ }^{28}$. From a structural point of view, a XA sub-unit can be distinguished from the phenoxazine unit of ommatins (red in Fig. 9). The $O$ bonds of both phenoxazine and phenoxazone units can be hydrolysed by light exposition in aqueous acid medium, which leads to uncyclised forms ${ }^{22,41}$. Since, the dissolution of shell fragments was conducted in aqueous acid conditions, such degradation can partially explain the identification of a XA sub-molecular unit among the ommochrome pigments of PF investigated by tandem mass spectrometry, especially the fragmentation patterns of Fig. $4 \mathrm{~d}$ and Fig. $6 \mathrm{a}$, where $\mathrm{C}_{8} \mathrm{H}_{4} \mathrm{NO}^{+}, \mathrm{C}_{10} \mathrm{H}_{4} \mathrm{NO}_{3}{ }^{+}, \mathrm{C}_{10} \mathrm{H}_{4} \mathrm{NO}_{3}{ }^{+}$and $\mathrm{C}_{11} \mathrm{H}_{6} \mathrm{NO}_{5}{ }^{+}$ may correspond to $\left[\mathrm{X}-2 \mathrm{H}-\mathrm{H}_{2} \mathrm{O}-2 \mathrm{CO}\right]^{+},\left[\mathrm{XA}-2 \mathrm{H}-\mathrm{H}_{2} \mathrm{O}\right]^{+},[X A-2 \mathrm{H}]^{+}$and $[\mathrm{XA}-2 \mathrm{H}+\mathrm{CO}]^{+}$, respectively. To date, two main biosynthetic pathways of ommochrome pigments have been proposed, both involving XA. The first involves the condensation of XA with 3-hydroxyanthranilic acid and/or 3-hydroxykynurenine ${ }^{27}$. The second involves only 3-hydroxykynurenine (3-HK) as an intermediate by condensation of two units ${ }^{28}$. In this case, XA is described as a side product of the intramolecular cyclisation of 3-HK or as a degradation product of xanthommatin. Such similar processes could occur in our study, XA being either a metabolite produced in excess or a degradation product of multiple possible origin (during dissolution/extraction, biosynthesis or during the life evolution of the shell).

The potential presence of carboxylated/decarboxylated, oxidised/reduced, hydroxylated, hydrated, sulphated and potentially esterified concomitant forms was observed from the structural investigation of double-charged ions, that is also compatible with ommochromes, known to produce carboxylated/decarboxylated, oxidised/reduced, sulphated forms as shown in Fig. 9, depending on their reactivity in solution ${ }^{22}$. Their molecular weight, higher than those of ommatins, and the numerous carboxyl groups of their structure, may be more coherent with the polymeric/oligomeric nature of ommins. However, there is neither unambiguous characterisation of such class of ommochromes in the literature nor available commercial standard to confirm this assumption. 
Whatever is the definitive structure of these compounds, it shows a high number of carboxylic function that remind the several carboxylic groups of uroporphyrin and derivatives. It suggests an important function throughout the mineralisation process of the shell. Their occurrence is consistent with the binding of pigments to the calcite part of the shell via an ionic pigment- $\mathrm{Ca}^{2+}$ bond, that is also suitable for the transport and fixation of calcium in the shell. It remains to be elucidated whether this was selected by nature, in order to ensure the binding of pigments designed for a specific function, or whether pigments are a carboxylic-rich by-product of the physiology of the animal resulting in their coincidental accumulation on the shell surface.

In the present study, we evidence the presence of ommochromes in a bivalve, namely Crassostrea gigas, as well as the absence of eumelanin and pheomelanin among the acid-soluble pigments of the purple colour of its shells. Besides porphyrins that we recently reported, the presence of ommochromes are supported by the solubility, luminescence and UV-visible absorption of the acid soluble pigments. Furthermore, the identification of xanthurenic acid is of prime importance and has led to a partial elucidation of the structure of these ommochromes, although pieces of the puzzle are still missing, and would require comparison with standard substances once commercially available.

Experiments on the mantle edge epithelium by a non- or soft-destructive process could also give reliable information on the structure of coloured pigments, and could allow to rely a potential function in living conditions. To date, their strong absorption in the visible region suggests a potential protection against light but other properties could emerge, eventually related to an oxidation process as observed in the production of uroporphyrin and derivatives ${ }^{7,8}$.

\section{Declarations}

\section{Data availability}

The data that support the findings of this study are available from the corresponding authors on reasonable request.

\section{Acknowledgments}

We gratefully acknowledge TARBOURIECH-MEDITHAU and the PILE-CIFRE program from the Région Occitanie/Pyrénées-Méditerranée for financial support. We also thank Guillaume Cazals from the Laboratoire de Mesures Physiques for RPLC-Q-ToF-HRMS and MS/MS analysis.

\section{Author contributions}

M.B., B.B., and I.P. conceived the framework, conducted the structural investigations and wrote the text.

\section{Competing interests}

The authors declare no competing interests. 
Correspondence and requests for materials should be addressed to B.B. or I.P.

\section{References}

1. Williams, S. T. Molluscan shell colour. Biol. Rev.92, 1039-1058 (2017).

2. Comfort, A. Acid-soluble pigments of shells. 1. The distribution of porphyrin fluorescence in molluscan shells. Biochem. J.44, 111-117 (1949).

3. Williams, S. T. et al. Identification of shell colour pigments in marine snails Clanculus pharaonius and C. margaritarius (Trochoidea; Gastropoda). PLoS ONE11, e0156664 (2016).

4. Stenger, P.-L. et al. Molecular pathways and pigments underlying the colors of the pearl oyster Pinctada margaritifera var. cumingii (Linnaeus 1758). Genes12, 421 (2021).

5. Affenzeller, S., Wolkenstein, K., Frauendorf, H. \& Jackson, D. J. Eumelanin and pheomelanin pigmentation in mollusc shells may be less common than expected: insights from mass spectrometry. Front. Zool.16, 47 (2019).

6. Hao, S. et al. Extraction and identification of the pigment in the adductor muscle scar of Pacific oyster Crassostrea gigas. PLoS ONE10, e0142439 (2015).

7. Bonnard, M., Cantel, S., Boury, B. \& Parrot, I. Chemical evidence of rare porphyrins in purple shells of Crassostrea gigas oyster. Sci. Rep.10, 12150 (2020).

8. Hu, B., Li, Q., Yu, H. \& Du, S. Identification and characterization of key haem pathway genes associated with the synthesis of porphyrin in Pacific oyster (Crassostrea gigas). Comp. Biochem. Physiol. B Biochem. Mol. Biol.255, 110595 (2021).

9. Feng, D., Li, Q., Yu, H., Kong, L. \& Du, S. Transcriptional profiling of long non-coding RNAs in mantle of Crassostrea gigas and their association with shell pigmentation. Sci. Rep.8, 1436 (2018).

10. Saenko, S. V. \& Schilthuizen, M. Evo-devo of shell colour in gastropods and bivalves. Curr. Opin. Genet. Dev.69, 1-5 (2021).

11. Affenzeller, S., Wolkenstein, K., Frauendorf, H. \& Jackson, D. J. Challenging the concept that eumelanin is the polymorphic brown banded pigment in Cepaea nemoralis. Sci. Rep.10, 2442 (2020).

12. Solano, F. Melanins: skin pigments and much more-types, structural models, biological functions, and formation routes. New J. Sci.2014, 1-28 (2014).

13. Feifei, Y. et al. Identification of a tyrosinase gene and its functional analysis in melanin synthesis of Pteria penguin. Gene656, 1-8 (2018). 
14. Chen, X., Liu, X., Bai, Z., Zhao, L. \& Li, J. HcTyr and HcTyp-1 of Hyriopsis cumingii, novel tyrosinase and tyrosinase-related protein genes involved in nacre color formation. Comp. Biochem. Physiol. B Biochem. Mol. Biol.204, 1-8 (2017).

15. Miyamoto, H. et al. The diversity of shell matrix proteins: genome-wide investigation of the pearl oyster, Pinctada fucata. Zoolog. Sci.30, 801 (2013).

16. Lemer, S., Saulnier, D., Gueguen, Y. \& Planes, S. Identification of genes associated with shell color in the black-lipped pearl oyster, Pinctada margaritifera. BMC Genomics16, 568 (2015).

17. Ding, J. et al. Transcriptome sequencing and characterization of Japanese scallop Patinopecten yessoensis from different shell color lines. PLoS ONE10, e0116406 (2015).

18. Miyashita, T. \& Takagi, R. Tyrosinase causes the blue shade of an abnormal pearl. J. Molluscan Stud.77, 312-314 (2011).

19. Linzen, B. The tryptophan $\rightarrow$ ommochrome pathway in Insects. in Advances in Insect Physiology vol. 10 117-246 (Elsevier, 1974).

20. Needham, A. E. Zoophysiology and Ecology, Volume 3: The Significance of Zoochromes. vol. 3 (Springer-Verlag Berlin, 1974).

21. Bandaranayake, W. M. The nature and role of pigments of marine invertebrates. Nat. Prod. Rep.23, 223 (2006).

22. Figon, F. \& Casas, J. Ommochromes in invertebrates: biochemistry and cell biology. Biol. Rev.94, 156183 (2019).

23. Williams, T. L. et al. Dynamic pigmentary and structural coloration within cephalopod chromatophore organs. Nat. Commun.10, 1004 (2019).

24. Hsiung, B.-K., Blackledge, T. A. \& Shawkey, M. D. Spiders do have melanin after all. J. Exp. Biol.218, $3632-3635$ (2015).

25. Ostrovsky, M. A., Zak, P. P. \& Dontsov, A. E. Vertebrate eye melanosomes and invertebrate eye ommochromes as screening Cell organelles. Biol. Bull.45, 570-579 (2018).

26. Cordell, G. A. \& Daley, S. Biosynthesis of the ommochromes and papiliochromes. Rec. Nat. Prod.15, 420-432 (2021).

27. Panettieri, S., Gjinaj, E., John, G. \& Lohman, D. J. Different ommochrome pigment mixtures enable sexually dimorphic Batesian mimicry in disjunct populations of the common palmfly butterfly, Elymnias hypermnestra. PLoS ONE13, e0202465 (2018). 
28. Figon, F. et al. Uncyclized xanthommatin is a key ommochrome intermediate in invertebrate coloration. Insect Biochem. Mol. Biol.124, 103403 (2020).

29. Huijser, A., Pezzella, A. \& Sundström, V. Functionality of epidermal melanin pigments: current knowledge on UV-dissipative mechanisms and research perspectives. Phys. Chem. Chem. Phys.13, 9119 (2011).

30. Esparza-Espinoza, D. M. et al. Chemical structure and antioxidant activity of cephalopod skin ommochrome pigment extracts. Food Sci. Technol. (2021).

31. Verdes, A. et al. Nature's palette: characterization of shared pigments in colorful avian and mollusk shells. PLOS ONE10, e0143545 (2015).

32. Butenandt, A., Schiedt, U. \& Biekert, E. Über ommochrome, II. Mitteilung. Alkalischer und fermentativer abbau von xanthommatin und rhodommatin. Alkalischer abbau der kynurenin-seitenkette. Justus Liebigs Ann. Chem.586, 229-239 (1954).

33. Butenandt, A., Biekert, E., Koga, N. \& Traub, P. Über ommochrome, XXI. Konstitution und synthese des ommatins D. Hoppe-Seyler's Z. Für Physiol. Chem.321, 258-275 (1960).

34. Lindstedt, C. et al. Characterizing the pigment composition of a variable warning signal of Parasemia plantaginis larvae: pigment composition of a warning signal. Funct. Ecol.24, 759-766 (2010).

35. Nijhout, H. F. Ommochrome pigmentation of the linea and rosa seasonal forme Precis coenia (Lepidoptera: Nymphalidae). Achives Insect Biochem. Physiol.36, 215-222 (1997).

36. Daniels, E. V. \& Reed, R. D. Xanthurenic acid is a pigment in Junonia coenia butterfly wings. Biochem. Syst. Ecol.44, 161-163 (2012).

37. Fujiwara, M. et al. Xanthurenic acid is the main pigment of Trichonephila clavata gold dragline silk. Biomolecules11, 563 (2021).

38. Thane, C. \& Reddy, S. Processing of fruit and vegetables: effect on carotenoids. Nutr. Food Sci.97, 5865 (1997).

39. Mezzomo, N. \& Ferreira, S. R. S. Carotenoids functionality, sources, and processing by supercritical technology: A review. J. Chem.2016, 1-16 (2016).

40. Holl, A. Coloration and chromes. in Ecophysiology of Spiders (ed. Nentwig, W.) 16-25 (Springer Berlin Heidelberg, 1987).

41. Bolognese, A. \& Liberatore, R. Photochemistry of ommochrome pigments. J. Heterocycl. Chem.25, 1243-1246 (1988). 
Figures
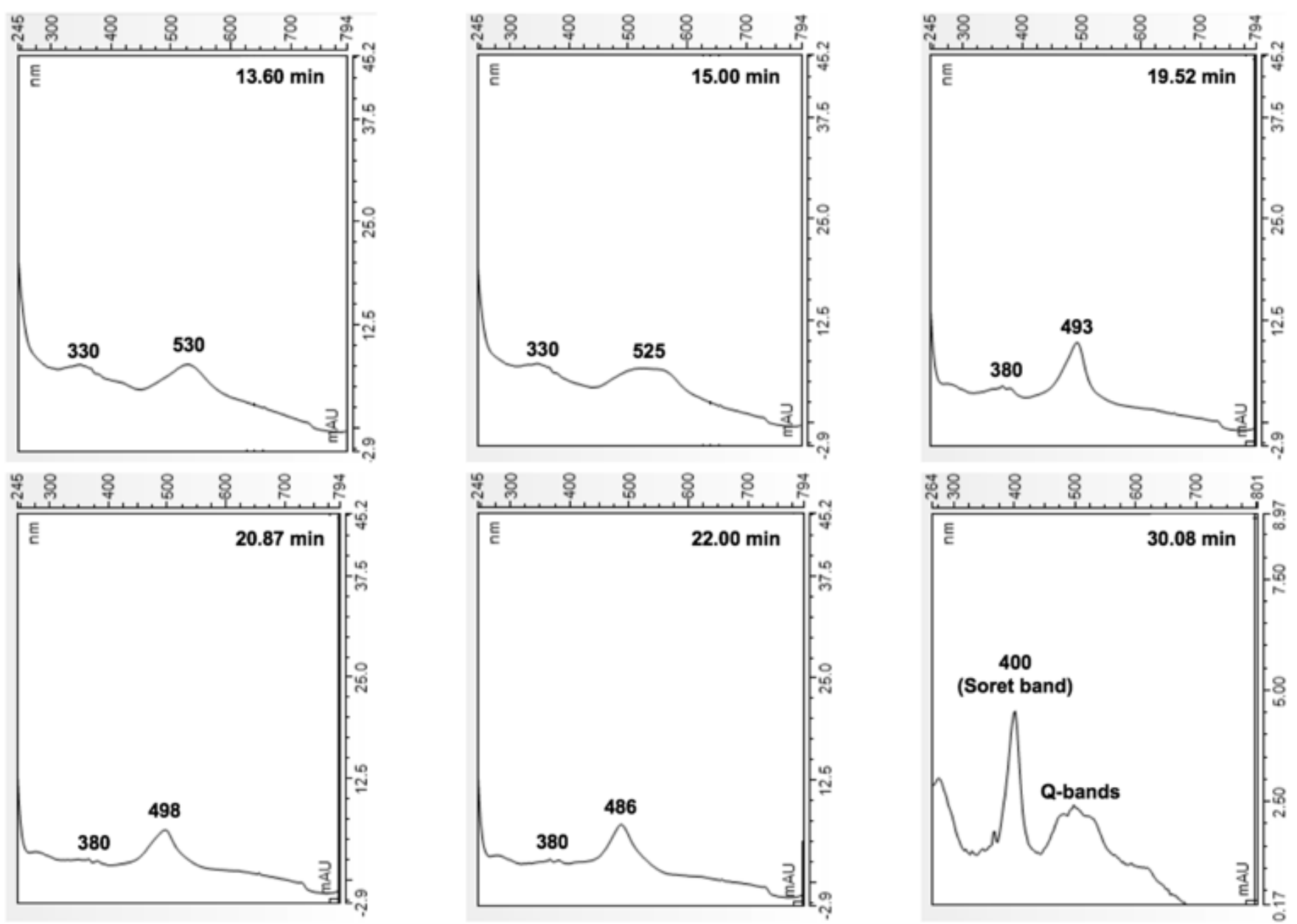

Figure 1

UV-vis absorption spectra of acid-soluble pigments of purple fragments of shells of C. gigas at different elution times. 
a Chromatogram obtained at $500 \mathrm{~nm}$
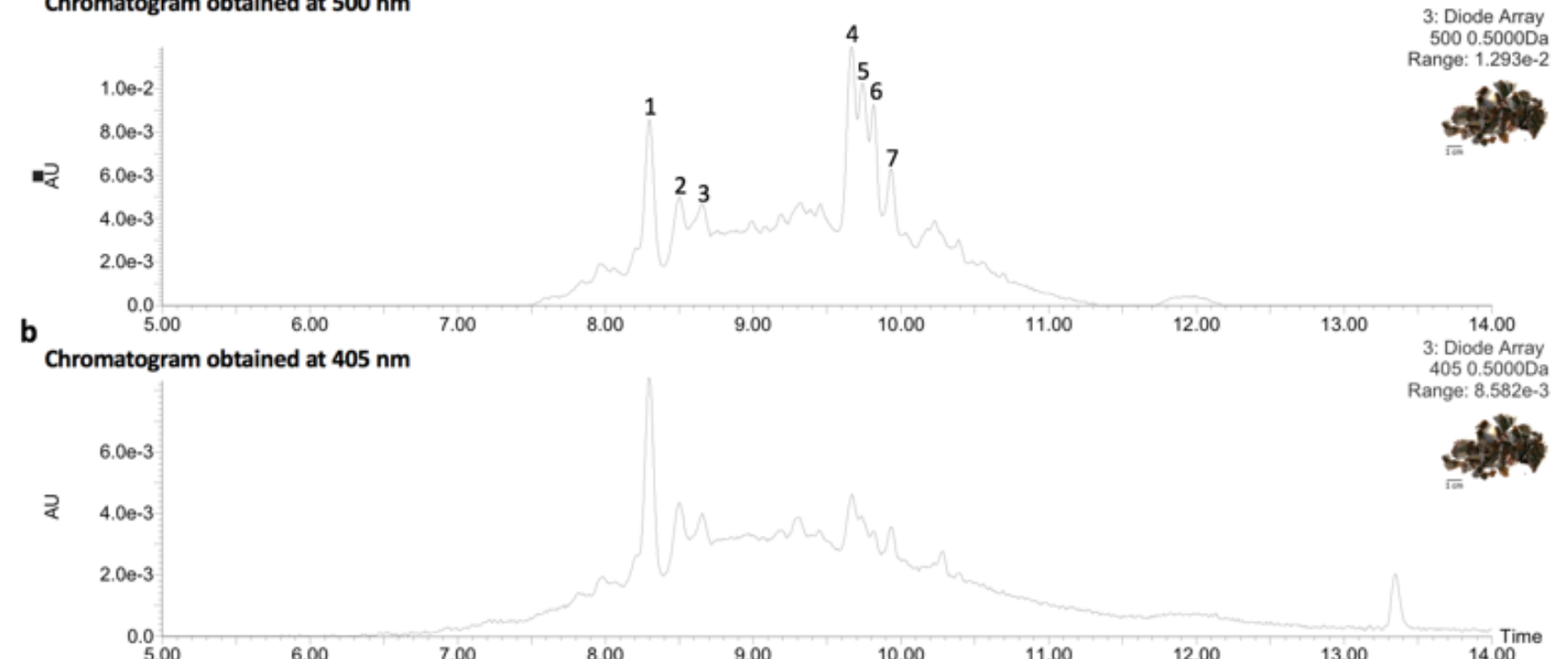

C

High resolution mass spectrum at $8.30 \mathrm{~min}$

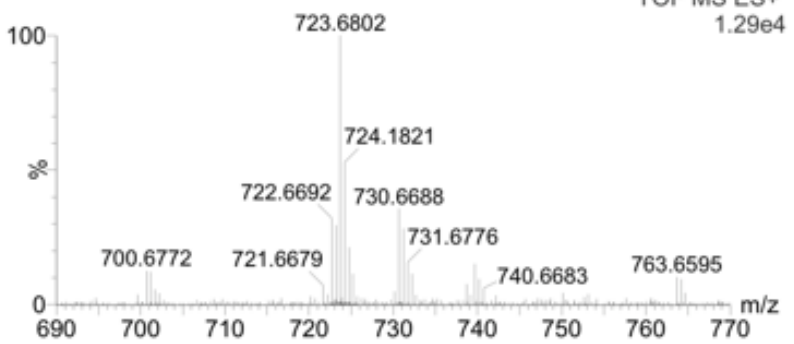

d
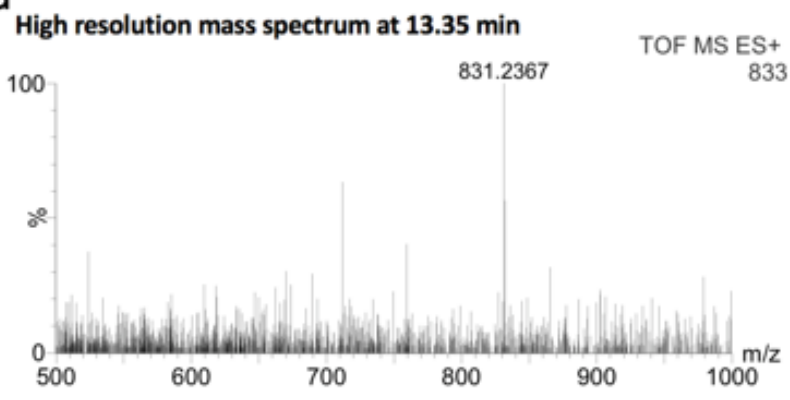

\section{Figure 2}

Characterisation by RPLC-Q-ToF-HRMS-UV-vis of purple fragments of shells of C. gigas dissolved in $1 \mathrm{M}$ $\mathrm{HCl}(\mathrm{aq})$. a Chromatogram obtained at $500 \mathrm{~nm}$. b Chromatogram obtained at $405 \mathrm{~nm}$. c High resolution mass spectrum at $8.30 \mathrm{~min}$. $\mathrm{d}$ High resolution mass spectrum at $13.35 \mathrm{~min}$ (uroporphyrin I or III molecular ion). 


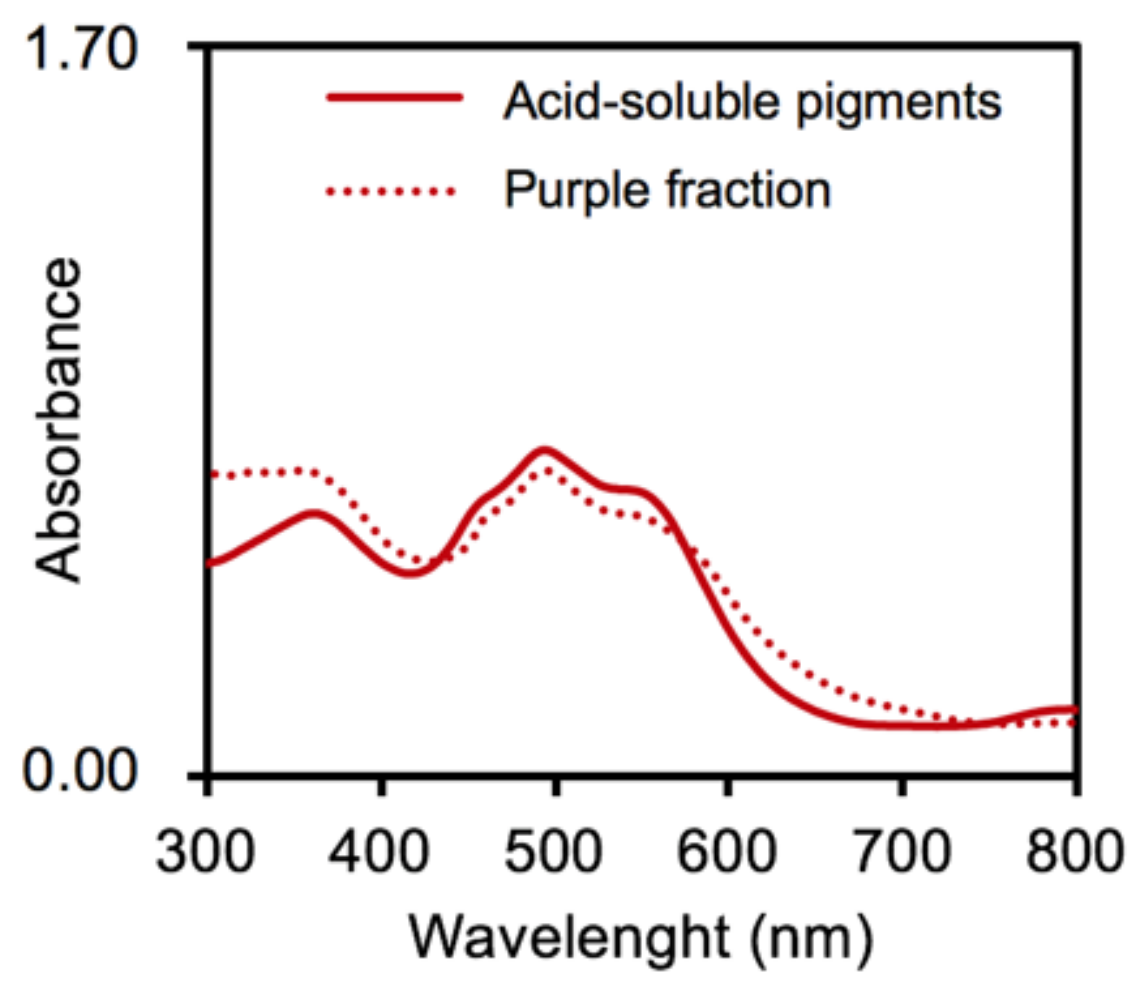

Figure 3

Absorption spectra of acid-soluble pigments obtained by the dissolution of purple shell fragment followed by filtration compared with the purple fraction solubilised in $1 \mathrm{M} \mathrm{HCl}(\mathrm{aq})$.

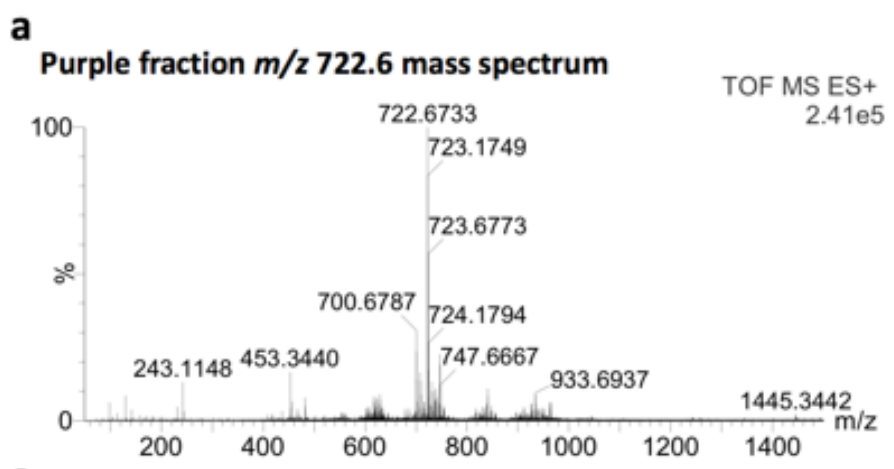

C

Purple fraction $m / z 762.6$ mass spectrum

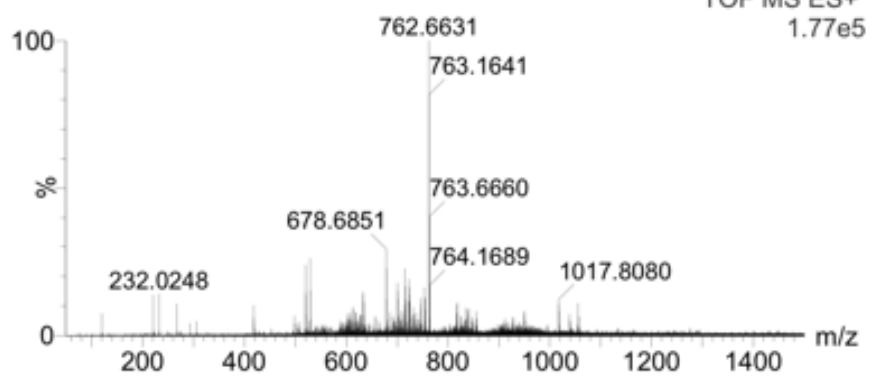

b

Tandem fragmentation mass spectrum

TOF MSMS 722.88ES+
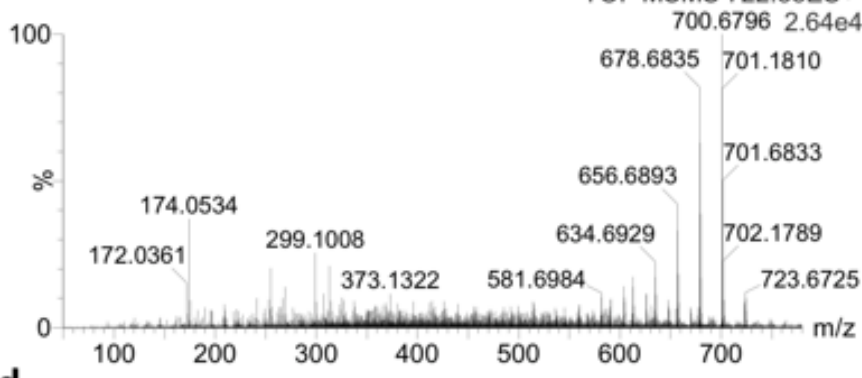
d

Tandem fragmentation mass spectrum TOF MSMS 763.76ES+

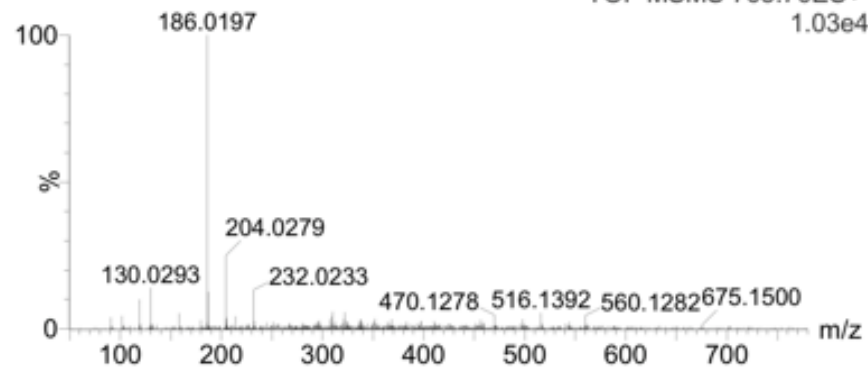

Figure 4 
Tandem mass fragmentation in positive ionisation mode of major double-charged ions from PF. a-b Tandem mass fragmentation of $[\mathrm{M}+2 \mathrm{H}] 2+\mathrm{m} / \mathrm{z}$ at 722.6733 (exact mass $=1443.3310 \mathrm{Da}$ ). $\mathrm{c}-\mathrm{d}$ Tandem mass fragmentation of $[\mathrm{M}+2 \mathrm{H}] 2+\mathrm{m} / \mathrm{z}$ at 762.6631 (exact mass $=1523.3106 \mathrm{Da}$ ).

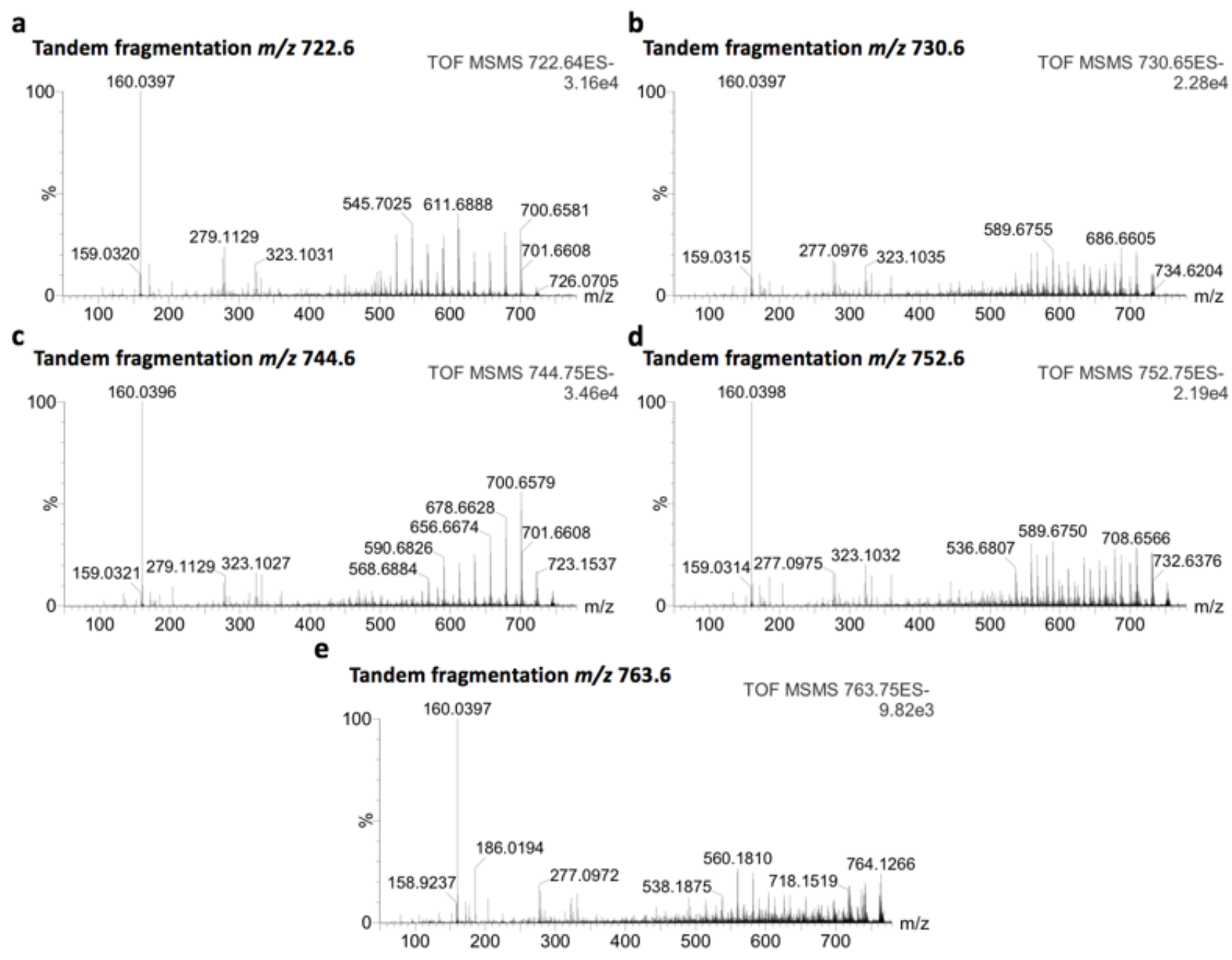

\section{Figure 5}

Tandem mass fragmentation in negative ionisation mode of major double-charged ions from PF. a Tandem mass fragmentation of $[\mathrm{M}-2 \mathrm{H}] 2-\mathrm{m} / \mathrm{z}$ at 722.6521 (exact mass $=1447.3198 \mathrm{Da}$ ). $\mathrm{b}$ Tandem mass fragmentation of $[\mathrm{M}-2 \mathrm{H}] 2-\mathrm{m} / \mathrm{z}$ at 730.6509 (exact mass $=1463.3174 \mathrm{Da}$ ). $\mathrm{c}$ Tandem mass fragmentation of $[\mathrm{M}-2 \mathrm{H}] 2-\mathrm{m} / \mathrm{z}$ at 744.6485 (exact mass $=1491.3126 \mathrm{Da}) \cdot \mathrm{d}$ Tandem mass fragmentation of $[\mathrm{M}-2 \mathrm{H}] 2-\mathrm{m} / \mathrm{z}$ at 752.6471 (exact mass $=1507.3058 \mathrm{Da}$ ). e Tandem mass fragmentation of $[\mathrm{M}-2 \mathrm{H}] 2-\mathrm{m} / \mathrm{z}$ at 763.6391 (exact mass $=1529.2938 \mathrm{Da}$ ). 


\section{a}

Tandem fragmentation mass spectrum in positive ionisation mode of compound \#1

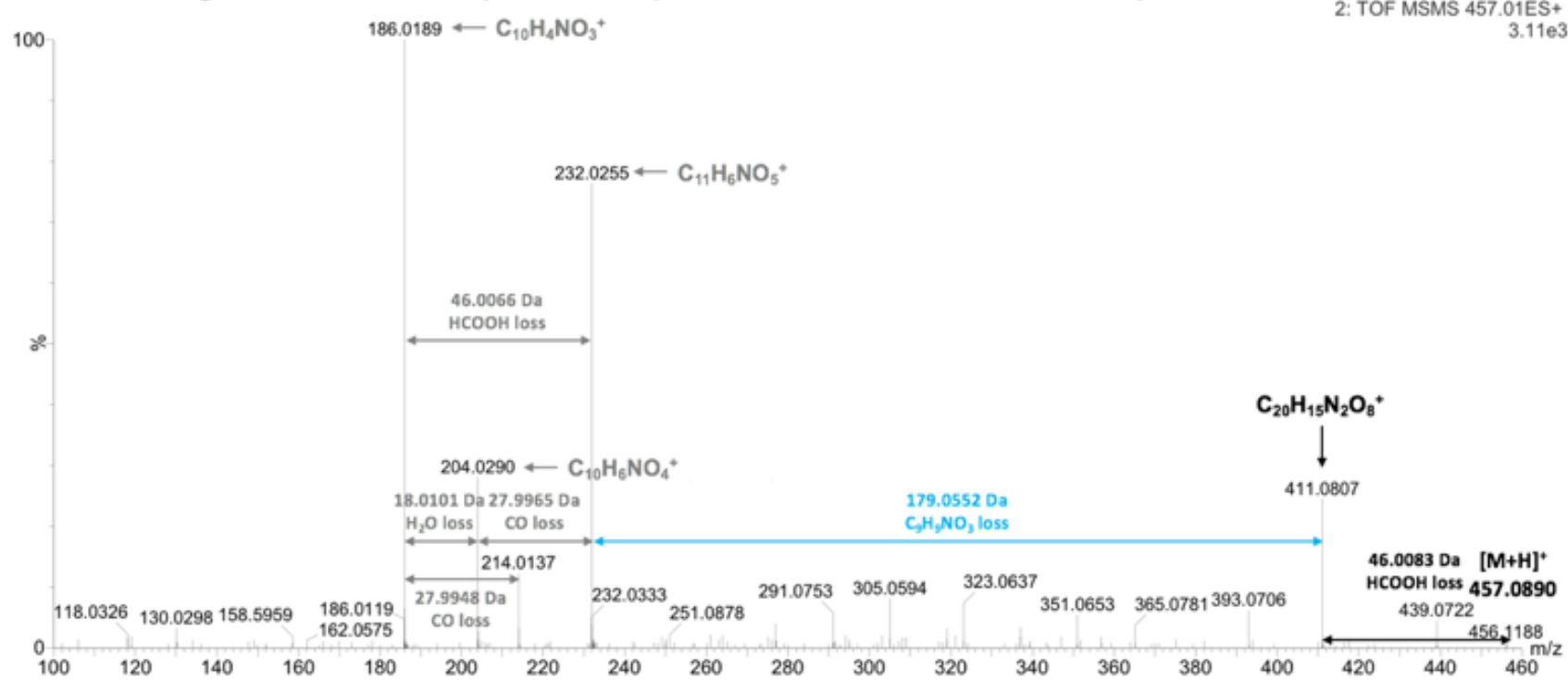

b

Tandem fragmentation mass spectrum in negative ionisation mode of compound \#1

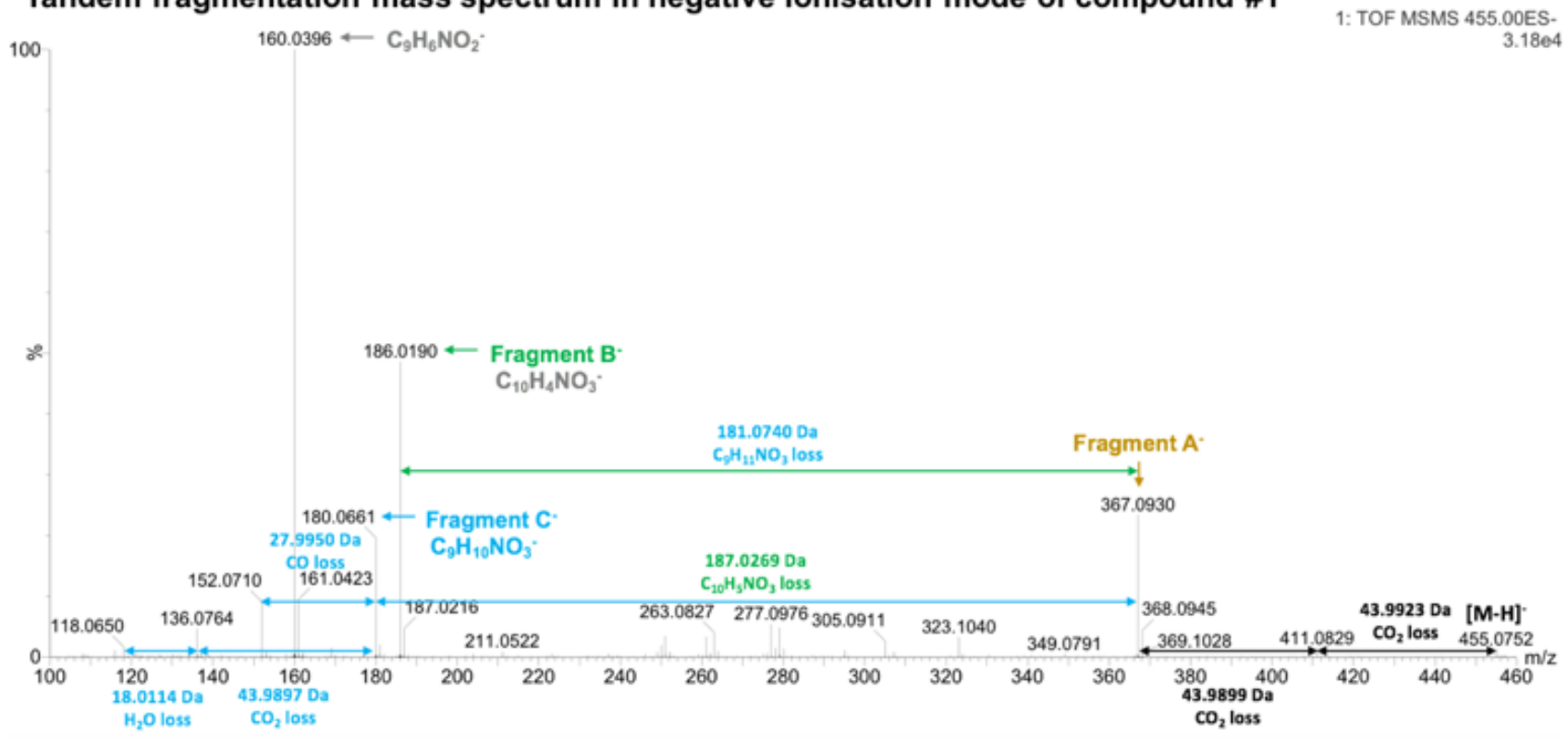

Figure 6

MS/MS spectra of compound \#1. a MS/MS spectrum obtained in positive ionisation mode. b MS/MS spectrum obtained in negative ionisation mode. 

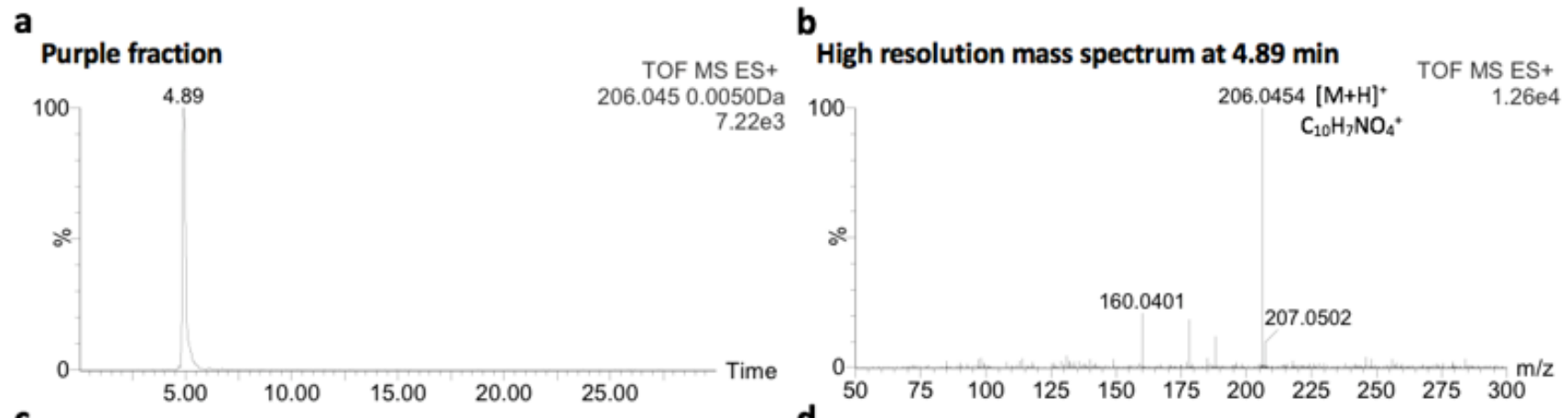

C

Tandem fragmentation mass spectrum TOF MSMS 206.02ES+

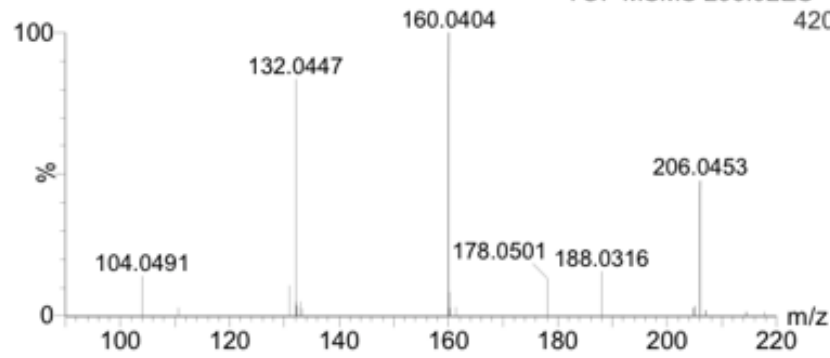

d

Tandem fragmentation mass spectrum TOF MSMS 204.05ES-

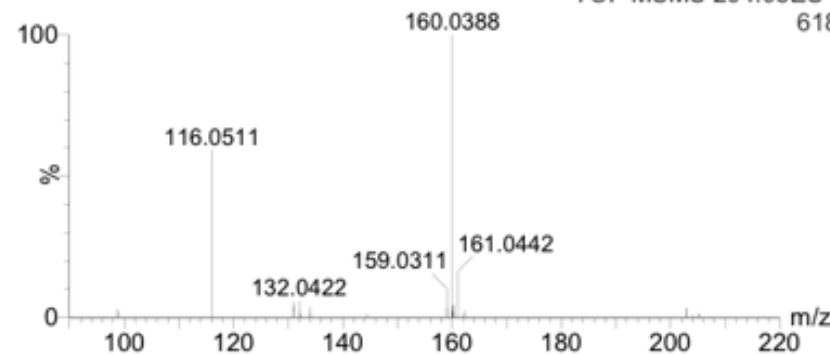

e

Xanthurenic acid chemical standard

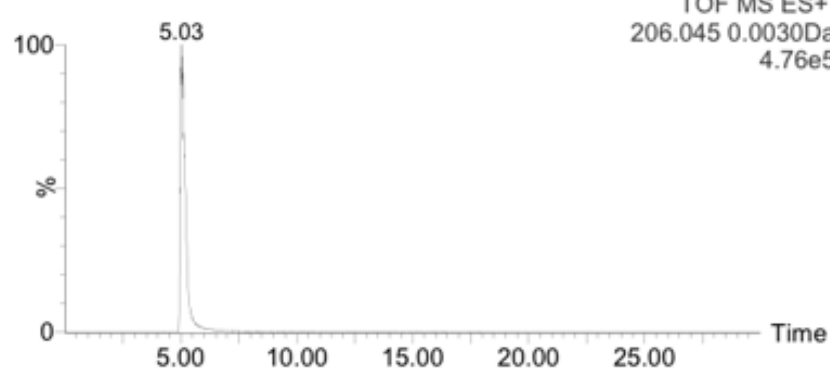

g

Tandem fragmentation mass spectrum TOF MSMS 206.02ES+

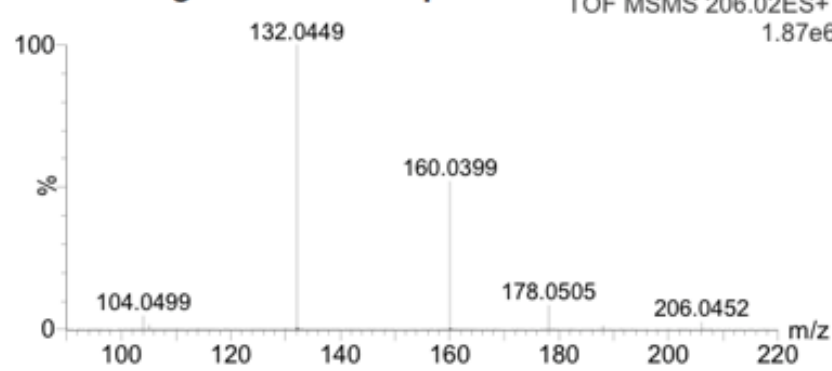

f

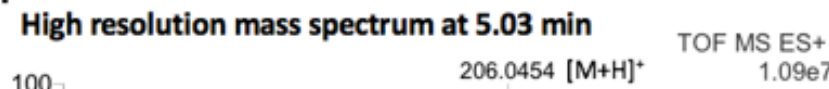
100 $\mathrm{C}_{10} \mathrm{H}_{7} \mathrm{NO}_{4}{ }^{+}$

h
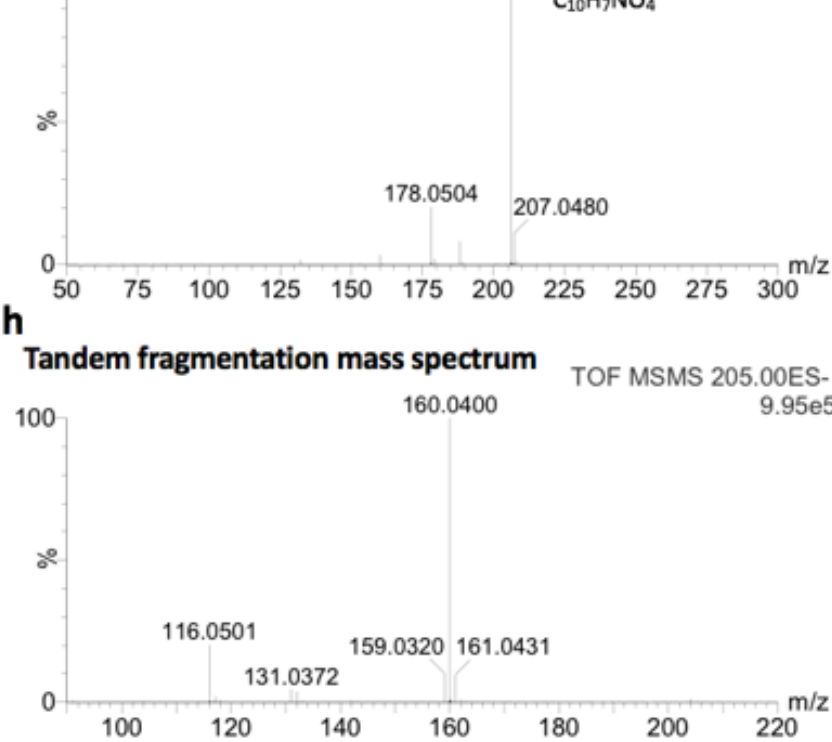

Figure 7

Comparative identification of xanthurenic acid in PF. a Extracted chromatogram of xanthurenic acid molecular ion in PF. b High resolution mass spectra of xanthurenic acid eluted at 4.89 min from PF. c-d Tandem fragmentation mass spectra of xanthurenic acid from PF, positive and negative ionisation mode, respectively. e Extracted chromatogram of xanthurenic acid molecular ion from the chemical standard. $f$ High resolution mass spectra of xanthurenic acid eluted at $5.03 \mathrm{~min}$ from the chemical standard. g-h Tandem fragmentation mass spectra of xanthurenic acid from the chemical standard, positive and negative ionisation mode, respectively. 


\section{a}

Sepia officinalis eumelanin

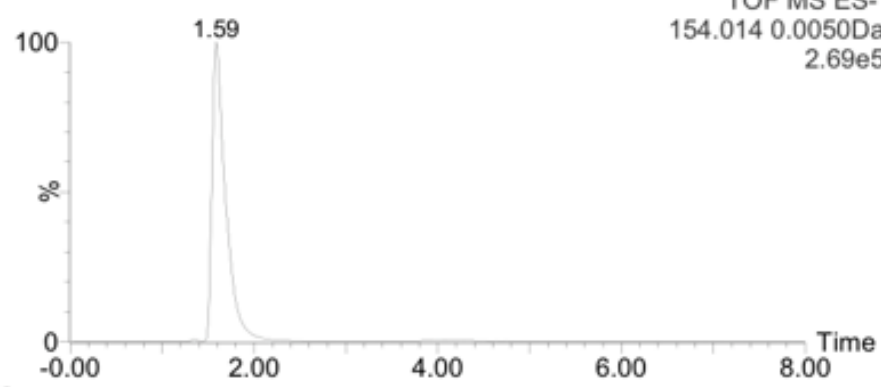

C

PDCA extracted chromatogram obtained from PF TOF MS ES-

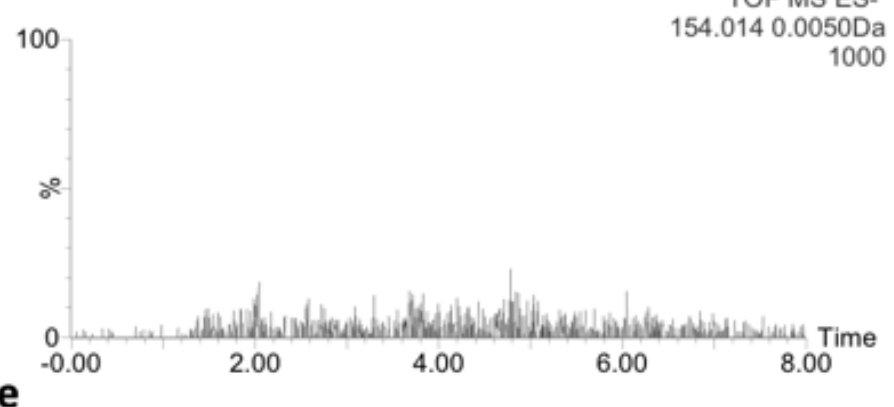

TDCA extracted chromatogram obtained from PF TOF MS ES-

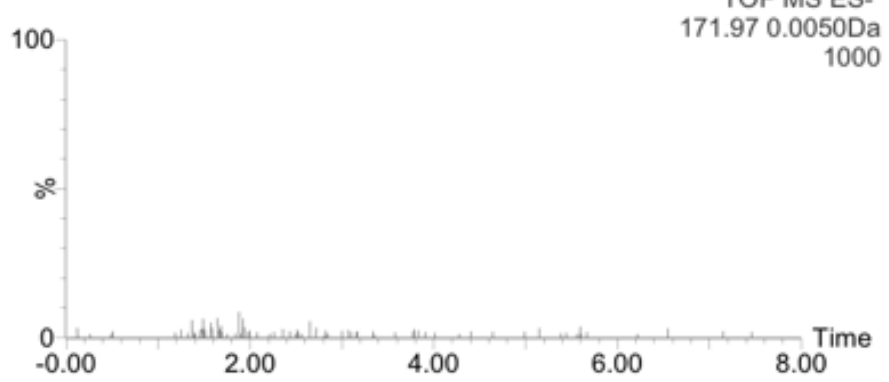

b

High resolution mass spectrum at $\mathbf{1 . 5 9} \mathbf{m i n}$ TOF MS ES-

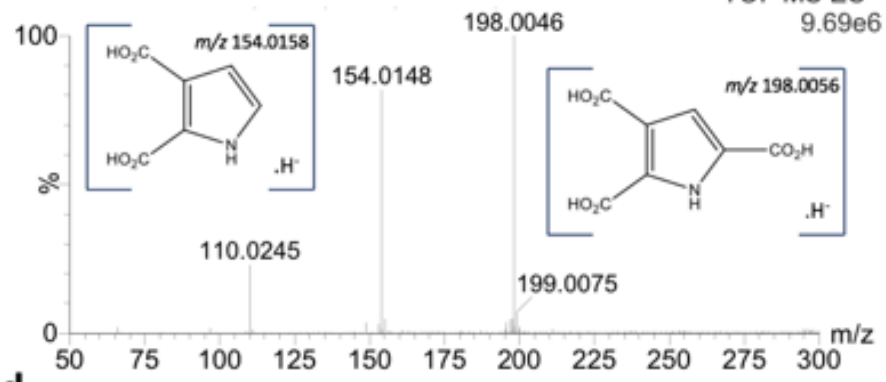

d

PTCA extracted chromatogram obtained from PF TOF MS ES-

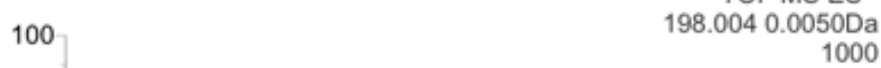

\section{Figure 8}

Comparative analysis of Sepia officinalis eumelanin and purple fraction. a Extracted chromatogram of eumelanin oxidation products. b High resolution mass spectra of Sepia officinalis eumelanin oxidation products at 1.59 min. c-f Extracted chromatograms of PDCA, PTCA, TDCA and TTCA from the purple fraction after alkaline oxidation, respectively (background noise). 

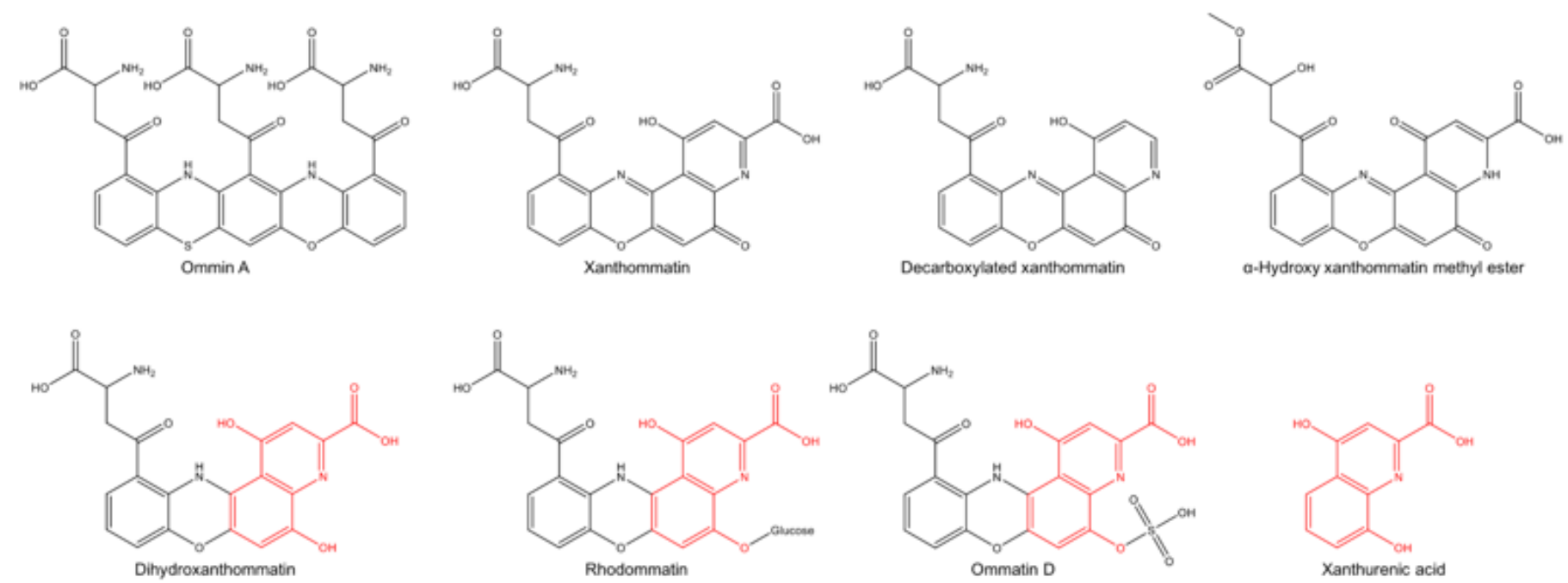

Figure 9

Structure of ommin A, some known ommatins and xanthurenic acid.

\section{Supplementary Files}

This is a list of supplementary files associated with this preprint. Click to download.

- IParrotetal.SupplementaryInformation.pdf 